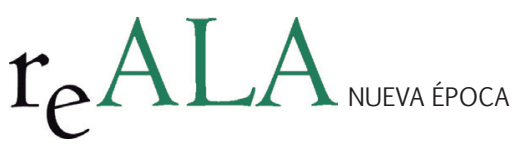

REALA, n 3, enero-junio 2015 ISSN: 1989-8975

DOI: http://dx.doi.org/10.24965/reala.voi3.10245

\title{
Régimen jurídico básico de las relaciones de puestos de trabajo y estatuto de los funcionarios locales
}

\author{
Agustín Juan Gil Franco \\ Funcionario de la Escala Técnica de Universidades, al servicio del Ayuntamiento de Madrid \\ Profesor Asociado de Derecho Administrativo de la Universidad Politécnica de Madrid \\ gilfa@madrid.es
}

\section{Resumen}

El Estatuto Básico del Empleado Público, lejos de aclarar el sistema de ordenación de los recursos humanos en las Administraciones públicas, abre la puerta a que puedan generarse diversos modelos de función pública. De igual forma, en el ámbito local la carencia de una regulación sistemática del estatuto de funcionarios propios al servicio de las Administraciones locales hace necesario extraer de las normas estatales su contenido básico que, por otro lado, se ha venido constatado por la propia realidad administrativa de las Corporaciones locales: todas poseen o una RPT o un catálogo de puestos de trabajo y, desde luego, una plantilla. Por otro lado, se aborda, desde un punto vista meramente introductorio, el impacto del concepto y contenido de las relaciones de puestos de trabajo en el estatuto funcionarial local y las consecuencias para la carrera de éstos.

Palabras clave

Normas reglamentarias básicas, funcionarios locales, carrera administrativa, relaciones de puestos de trabajo y plantillas

\section{Basic legal framework of the relations of jobs and status of local officials}

\footnotetext{
Abstract

The Basic Statute of Public Employees, far from clarifying the system of management of human resources in public administrations, opens the door to various models that can be generated for public service. Similarly, at the local level the lack of a systematic regulation of the status of themselves in the service of local government officials is necessary to extract the basic content rules state, on the other hand, has been noted by the administrative reality itself of the local governments: all have or RPT or a catalog of jobs and, of course, a template. On the other hand, is discussed from a view point merely introductory, the impact of the concept and content of relations jobs in the local civil service status and career implications of these
}

Key words

Basic regulations, local officials, administrative careers, relations jobs and templates civil servants. 


\section{SUMARIO}

1. Régimen jurídico en el ámbito local. Sistema de fuentes. 1.1 El sistema de fuentes reguladoras de las RPT y el contenido básico de éstas. 1.2 Contenido básico inferible de normas reglamentarias estatales. 1.3 Relaciones de puestos de trabajo y estatuto formal de los funcionarios locales.

2. Otros instrumentos de ordenación de los empleados públicos junto con las relaciones de puestos de trabajo en las Administraciones locales 2.1 Instrumentos de carácter previo: Catálogos de puestos de trabajo 2.2 Instrumentos adicionales: Plantillas orgánicas y presupuestos municipales

3. Naturaleza jurídica de las RPT. 3.1 Elemento normativo desgajado. 3.2 Carácter normativo de las RPT. Líneas jurisprudenciales

\section{RÉGIMEN JURÍDICO EN EL ÁMBITO LOCAL DE LAS RELACIONES DE PUESTOS DE TRABAJO SISTEMA DE FUENTES}

Aunque pudiéramos decir que el viejo debate entre el modelo de función pública abierto o cerrado quedó definitivamente enterrado en la Ley de Medidas para la Reforma de la Función pública, con la aprobación del sistema de las relaciones de puestos de trabajo (en adelante RPT) que se diseñaran por la precitada Ley, años después y con una implantación real casi exclusiva del desempeño del puesto a través de las RPT'1, podemos decir que el sistema español de función pública obedece en casi su totalidad al desempeño del puesto, siendo éste el núcleo indispensable dentro de la carrera profesional del funcionario. Sin embargo, algo que fácilmente podía constatarse en la realidad actual de las Administraciones públicas a través de sus modelos organizativos y de gestión de recursos humanos, y con el ordenamiento jurídico generado en torno a esta cuestión básica, ha podido tornarse en una vuelta al principio con la posibilidad abierta por el Estatuto Básico del Empleado Público (EBEP en lo sucesivo) de que cada Comunidad Autónoma pudiera optar por un modelo propio de función pública que, incluso, podría contraponerse al propio de la Administración General del Estado. En efecto el EBEP, establece que las Administraciones Públicas estructurarán su organización a través de relaciones de puestos de trabajo u otros instrumentos organizativos similares que comprenderán, al menos, la denominación de los puestos, los grupos de clasificación profesional, los cuerpos o escalas, en su caso, a que estén adscritos, los sistemas de provisión y las retribuciones complementarias. Apostillado que dichos instrumentos serán públicos². Artículo que poniéndose en relación con las posibilidades de carrera horizontal, sin necesidad de cambio de puesto de trabajo3 ${ }^{3}$, podría abonar la posibilidad de otro modelo de función pública distinto al actualmente implantado en el conjunto de las Administraciones públicas españolas. Tampoco son ajenas a ello las Administraciones locales dado que, conforme a las previsiones del art. 3.1 del propio EBEP, "el personal funcionario de las Entidades Locales se rige por la legislación estatal que resulte de aplicación, de la que forma parte este Estatuto y por la legislación de las Comunidades Autónomas, con respeto a la autonomía local”. He aquí, pues, el punto clave para la posible elección del modelo que hemos apuntado y que se propone en el mismo Estatuto: la autonomía local.

\subsection{El sistema de fuentes reguladoras de las RPT}

Es cierto que el EBEP no ayuda para nada en la labor de encontrar el lugar que corresponde a las RPT dentro del edificio normativo local, tanto en su papel dentro de la ordenación de los recursos humanos locales como en el establecimiento de sus estructuras administrativas, más allá del reglamento orgánico que cada corporación municipal pudiera establecer. Y ello es así porque, a la defectuosa sistematización de fuentes, se añade su disposición final derogatoria4, que nos lleva a añadir más dudas de las razonables sobre el papel conformador estatal del régimen jurídico y estatutario de los funcionarios propios de las corporaciones locales.

Por ello, teniendo como referencia la propia realidad administrativa implantada para la función publica en las diversas Entidades locales, y siguiendo el camino de la lógica jurídica, a la par de desentrañar los confusos

1 Con ligeras excepciones referidas a ámbitos específicos de la actividad administrativa desempeñados por Cuerpos especiales de funcionarios fuertemente jerarquizados y para los que el requisito de la antigüedad en el desempeño se ha antepuesto a otros. Por ejemplo, las organizaciones de recursos humanos en ámbitos del Cuerpo Nacional de Policía o de los Cuerpos de Policía Local /municipal.

2 Art 74 de la Ley $7 / 2007$, de 12 de abril, del Estatuto Básico del Empleado Público

3 Arts. 16.3 a) y 17.2 del EBEP

4 Disposición derogatoria única, letra e) de Ley 7/2007, de 12 de abril, del Estatuto Básico del Empleado Público («B.O.E.»13 abril) que, a su vez, dispone, mediatizando la acción legislativa derogatoria, a través de la Disposición Final cuarta, por otro lado reguladora de la entrada en vigor de la ley: "3. Hasta que se dicten las Leyes de Función Pública y las normas reglamentarias de desarrollo se mantendrán en vigor en cada Administración Pública las normas vigentes sobre ordenación, planificación y gestión de recursos humanos en tanto no se opongan a lo establecido en este Estatuto". 
términos de normativa reguladora de las relaciones de puestos de trabajo, se ha de encontrar, en primer término, qué legislación estatal les resulta de aplicación directa a las Administraciones locales; y, sobre todo, a falta de su definición expresa, su carácter básico a la hora de delimitar las potestades de organización de las diferentes Corporaciones locales. La ausencia de un estatuto de la función pública local y de un sistema de fuentes claro y preciso predicable para estos funcionarios, ha sido señalada por la doctrina. En efecto, la legislación básica de régimen local y su relación con la legislación básica de función pública local -ya que aquélla se limita a recoger exclusivamente las peculiaridades de la función pública local derivadas de sus características organizativas propias- se engarza con la dimensión objetiva o estructural de la función pública local, pero sin aspirar a configurar un régimen básico completo, porque para éste se remitía a la legislación básica general de función pública, que completaba el "estatuto básico de la función pública local”. Así pues, la legislación básica de régimen local se convertía en elemento "diferencial” del régimen general básico de función pública que se trasladaba al ámbito de la función pública local desde su propio "filtro" pero sin mayores pretensiones.

La referencia obligada, pues, pasa en primer lugar por lo establecido en la LRBRL al respecto: “Las Corporaciones locales formarán la relación de todos los puestos de trabajo existentes en su organización, en los términos previstos en la legislación básica sobre función pública. Corresponde al Estado establecer las normas con arreglo a las cuales hayan de confeccionarse las relaciones de puestos de trabajo, la descripción de puestos de trabajo tipo y las condiciones requeridas para su creación, así como las normas básicas de la carrera administrativa, especialmente por lo que se refiere a la promoción de los funcionarios a niveles y grupos superiores ". Y que con el sistema de fuentes establecido, en este caso, el“reformado" art. 92.1 de la LRBRL7, supone reafirmar este papel regulador básico del estatuto de los funcionarios locales propios para la legislación de régimen local general. Hecho que se reafirma, por partida doble, desde el reenvío realizado por el propio Texto Refundido las disposiciones legales vigentes en materia de Régimen Local de $1986^{\circ}$ a la legislación Estatal, y que se decanta de manera indubitada por el sistema de las RPTs como elemento basal en la carrera administrativa de los funcionarios locales.

Así pues, tras el EBEP ha de tenerse en cuenta ineludiblemente ambas disposiciones legislativas, tanto la LRBRL como el TRRL, en esta última su carácter básico parece estar fuera de toda duda, a pesar de las opiniones de alguna doctrina referidas al precitado Texto Refundido, tras el Tribunal Constitucional reafirmando su especial carácter básico para la función pública local. Así lo manifestó la STC 385/1993, de 23 de diciembre, en la que se declaró la inconstitucionalidad del inciso "conforme a su naturaleza" de la Disposición final séptima, apartado primero, letra b) LRL, en cuanto criterio utilizado en la citada disposición final para inferir el carácter básico de los preceptos contenidos en sus Títulos VI y VII, siendo precisamente en dicha disposición en la que la Sala ampara parte de su concepción e identificación de las bases en materia de función pública local9. Porque, "la definición de las bases, en el ámbito de la legislación compartida, tiene por objeto crear un marco normativo unitario, de aplicación a todo el territorio nacional, dentro del cual las Comunidades Autónomas dispongan de un margen de actuación que les permita, mediante la competencia de desarrollo legislativo, establecer los ordenamientos complementarios que satisfagan sus peculiares intereses ${ }^{10}$ ", aunque respetando el marco de la autonomía local. Algo que además propicia "las propias exigencias del principio constitucional de seguridad jurídica, [que] reclama la declaración expresa por el legislador estatal del carácter básico de su regulación al fin "de dotar de una determinación cierta y estable a los ámbitos respectivos de ordenación de las materias en las que concurren y se articulan las competencias básicas estatales y las legislativas y reglamentarias autonómicas" de desarrollo (STC 37/2002, de 14 de febrero, FJ 9 ; y en similar sentido SSTC 1/1982, de 28 de enero, FJ 1, y 197/1996, de 28 de noviembre, FJ 5.b, entre otras). Esa observancia de las garantías de certidumbre jurídica es necesaria "para asegurar que las Comunidades Autónomas conocer cuál es el marco básico al que deben someter su competencia de desarrollo legislativo" (STC 37/2002, FJ 9)"11".

Tras la alusión hecha respecto a las dos grandes normas referidas a las RPT, hemos de proseguir la "cascada" sistemática que viene a situarnos sobre "la legislación estatal que resulte de aplicación" tal como lo establece el

5 Fuentetaja Pastor, Jesús Ángel (2013) “La función pública local: asignatura pendiente de la autonomía local” Revista de Administración Pública, n 191. Pág. 427.

6 Es el art. 90.2 de la Ley 7/1985, de 2 de abril, Reguladora de las Bases del Régimen Local, el cual en nada se opone al EBEP. Que ha permanecido inalterado, tras la reforma operada por la Ley 27/2013, 27 diciembre, de racionalización y sostenibilidad de la Administración Local (LRSAL)

7 La nueva redacción dada al art. 92.1 por la LRSAL, establece que "los funcionarios al servicio de la Administración local se rigen, en lo no dispuesto en esta Ley, por la Ley 7/2007, de 12 de abril, del Estatuto Básico del Empleado Público, por la restante legislación del Estado en materia de función pública, así como por la legislación de las Comunidades Autónomas, en los términos del artículo 149.1.18. ㄹe la Constitución”.

8 Así es, el art. 126.4 del Real Decreto Legislativo 781/1986, de 18 de abril, por el que se aprueba el Texto Refundido de las disposiciones legales vigentes en materia de Régimen Local, también lo preconiza: "Las relaciones de los puestos de trabajo , que tendrán en todo caso el contenido previsto en la legislación básica sobre función pública, se confeccionarán con arreglo a las normas previstas en el artículo 90.2 de la Ley 7/1985, de 2 de abril"

9 STC del 14 de febrero de 2002 (ROJ: STC 37/2002) Cuestiones de inconstitucionalidad acumuladas núms. 71/94 y 243/95.

10 STC del 4 de julio de 1991 (ROJ: STC 147/1991). Conflictos positivos de competencia acumulados núms. 384/85, 407/85 y 340/89.

11 STC del 16 de enero de 2003 (ROJ STC 1/2003). Recurso de inconstitucionalidad 2987/95. 
EBEP, o "por la restante legislación del Estado en materia de función pública”, como afirma el actual art. 90.1 de la LRBRL, para encontrar la ubicación reguladora del régimen jurídico de las RPT en las Administraciones locales. Para ello, es necesario hacer referencia a las normas contenidas en la Ley 30/1984, de 2 de agosto, en cuyo art. 16 , se hace una alusión directa a las relaciones de puestos de trabajo en la Administración local que, según vimos, podría quedar afectada por el mismo régimen derogatorio que el previsto para el art. 90.2 de la LRBRL en relación con la disposición derogatoria del EBEP pero con la ya mencionada matización de la Disposición final cuarta del mismo. Es decir, debemos entender derogado el art. 16 de la Ley 30/1984, en la medida en que se dicte la ley de función pública local o estatuto correspondiente y, mientras ese hecho no se produzca -al menos para el ámbito de las Administraciones locales-, hemos de entender vigente el precitado art. 16 de la Ley 30/1984.

Por tanto, las Administraciones locales han de contemplar necesariamente en sus organizaciones y sistemas de función pública las RPTs, que, en consonancia con su contenido regulador básico, deberán incluir, en todo caso, la denominación, tipo y sistema de provisión de los puestos, las retribuciones complementarias que les correspondan y los requisitos exigidos para su desempeño. Al que se ha de añadir el necesario carácter público de éstas dada su condición cercana a las normas jurídicas ${ }^{12}$.

De igual forma, hemos de tener en cuenta dentro del régimen regulador de las RPT, el Real Decreto 861/1986, de 25 de abril, por el que se establece el régimen de las retribuciones de los Funcionarios de Administración Local, cuyo contenido básico es señalado explícitamente en el mismo, al desarrollar sendos artículos de la Ley 30/1984, a su vez, declarados básicos: "Ios mencionados artículos tienen la consideración de bases del régimen estatutario de los funcionarios públicos, y en consecuencia son aplicables al personal de todas las Administraciones Públicas de conformidad con lo establecido en el artículo 1.3 de la mencionada Ley 30/1984, de 2 de agosto", y ejercer además la habilitación de desarrollo reglamentario previsto por la LRBRL "con objeto de que las Corporaciones Locales puedan realizar los estudios, adaptaciones y valoraciones de puestos de trabajo que sirvan de base a una adecuada y eficaz implantación del nuevo sistema". Efectivamente, el precitado Real Decreto reafirma las RPTs, dentro de cada Corporación local, como elementos estructurales para la organización y planificación de su función pública e incidiendo en la valoración del puesto de trabajo como catalizador de los conceptos retributivos que deben ser contenidos en dichas relaciones junto al proceso que ha de ser llevado a cabo hasta la aprobación definitiva de aquéllas ${ }^{13}$, por lo que su carácter básico está fuera de toda duda.

\subsection{Contenido básico inferible de normas reglamentarias estatales}

Pero la cuestión que se suscita ahora es ¿en qué medida podemos hacer extensiva la cláusula de legislación básica estatal para las disposiciones reguladoras de las RPT en la Administración General del Estado, cuando la legislación básica a la que se remitía el art. 90.2 de la LRBRL no ha sido dictada? ¿Es posible deducir su carácter básico sobre la propia estructura y característica de dicha normativa? En nuestra opinión cabe atribuir efectos básicos a dicha normativa, en primer término, porque la doctrina del Tribunal Constitucional ha concedido estos efectos cuando del articulado se deduce claramente su condición básica: "en ese acervo jurisprudencial se exige la calificación expresa de tal carácter básico o, excepcionalmente, que la norma correspondiente posea una estructura de la que pueda inferirse esa condición con naturalidad. En definitiva, cabe añadir aquí, que resplandezca por notoriedad o, en otro lenguaje, que resulte evidente por sí misma. Con ello se hace siempre alusión a lo manifiesto o a lo obvio y, en suma, a lo que no necesita de una ulterior operación interpretativa ${ }^{14 "}$. Interpretación que el mismo Tribunal nos dice que debe operar con "dos criterios, el objetivo y el teleológico, mediante la calificación del contenido material de cada precepto y la averiguación de su finalidad (SSTC 15/1989, 153/1989 y 170/1989)15”. Es más, a falta de definición legal específica, "lo que sea en cada caso básico ha de determinarse mediante el examen del contenido preceptivo de unas disposiciones y otras y no predicarse genéricamente, sin esta indagación, como atributo de un cuerpo normativo determinado ${ }^{16 "}$.

12 A este respecto es interesante tener en cuenta la STS, contencioso sección 7, de 5 de febrero de 2014 (ROJ: STS 902/2014) N de Recurso: 2986/2012 |Ponente: VICENTE CONDE MARTIN DE HIJAS, en la que se ha producido un discutible cambio en la doctrina casacional del tribunal al negar no sólo ya su condición de normas jurídicas sino su asimilación a éstas para poder ser objeto de recurso de casación a través de la vía del art. 86.3 de la Ley 29/1998, de 13 de julio, reguladora de la Jurisdicción contencioso administrativa. Nosotros no compartimos dicha doctrina jurisprudencial, en consonancia, en parte, con el voto particular de uno de los magistrados, al considerar que las RPT tienen verdadera naturaleza normativa. Un comentario especialmente útil sobre la sentencia véase en Véase también el trabajo de Guillermo Ruiz Arnáiz “Relaciones de puestos de trabajo: ¿disposiciones generales o actos administrativos?”. El Consultor de los Ayuntamientos $n^{\circ}$ 9. Comentarios jurisprudenciales 5 al 29 May. 2014, Ref. 1028/2014, pág. 1028.

13 Así lo determina la Disposición Transitoria $2^{\text {a }}$ del Real Decreto 861/1986, de 25 de abril, por el que se establece el régimen de las retribuciones de los Funcionarios de Administración Local: "Hasta tanto se dicten por la Administración del Estado las normas con arreglo a las cuales hayan de confeccionarse las relaciones de puestos de trabajo, la descripción de puestos de trabajo-tipo y las condiciones requeridas para su creación, los Plenos de las Corporaciones Locales deberán aprobar un catálogo de puestos a efectos de complemento específico. Mientras no estén aprobadas tales normas, los catálogos únicamente podrán ser modificados mediante acuerdo del Pleno"

14 STC, del 23 de diciembre de 1993 (ROJ: STC 385/1993). Recursos núms. 826/86, 839/86 y 842/86.

15 STC, del 26 de junio de 1995 (ROJ: STC 102/1995) Recursos núms. 1.220/89, 1.232/89, 1.238/89, 1.239/89, 1.260/89 y 1.268/89.

16 STC, del 11 de diciembre de 1986 (ROJ: STC 158/1986). Conflicto competencia núm. 427/84. 
Y que condición de norma básica se ha de predicar no sólo de las leyes sino también de las disposiciones reglamentarias: "estas bases han de ser en principio normas legales, orgánicas rara vez y ordinarias en su mayor parte, pero también -si necesario fuere- reglamentarias, en el uso de la potestad que al Gobierno de la Nación otorga el art. 97 de la Constitución (STC 135/1992) 17", Ilegando incluso a asignarse un contenido básico sobre meros actos ejecutivos: "el mismo sentido las SSTC 48/1988 y 49/1988, en la primera de las cuales se establece que «excepcionalmente pueden considerarse básicos ciertos actos de ejecución, cuando por la naturaleza de la materia resultan complemento necesario para garantizar la consecución de la finalidad objetiva a que responde la competencia estatal sobre las bases», diciéndose en la segunda de dichas Sentencias, "que las bases pueden contener regulaciones detalladas de materia, aspectos concretos e incluso actos de ejecución» "cuando sean realmente imprescindibles para el ejercicio efectivo de competencias establecidas» ${ }^{18}$ ". Porque, a juicio del Tribunal ha de acudirse de forma inmediata a la solución del problema normativo regulador de la realidad concreta: "la noción de legislación básica sea de carácter material, pudiendo ésta incluir, en consecuencia, normas de rango infralegal, cuando dada la naturaleza de la regulación resulta manifiestamente irrazonable plasmarla en normas cuya modificación no puede hacerse con la agilidad necesaria"19". Así, por ejemplo, ante la inexistencia de normas reguladoras para elección de representantes sindicales de los funcionarios en la Comunidad Autónoma de Cantabria, el Tribunal otorgó carácter básico a una Resolución de 29 de enero de 1981, referida a las Corporaciones locales: "sino que tampoco cabía inferir materialmente a partir de una legislación estatal inexistente, como con reiteración se ha dicho. En aquel caso, la Comunidad Cántabra se apoyó en la Resolución de 29 de enero de 1981, referida a las Corporaciones locales. Pero en cuanto a la posibilidad de entender que la citada Resolución de 29 de enero de 1981 podría contener dicha regulación estatal básica ${ }^{20 "}$. Recientemente el propio Tribunal ha recalcado que, aunque el contenido y alcance de los preceptos básicos tienen un sentido distinto cuando en el ejercicio de las potestades de organización cada Administración dicta su propias disposiciones, no debe descartarse una regulación básica estatal incluso, en lo que afecta a los aspectos de organización interna y de funcionamiento, ya que dentro de éstas hay aspectos también básicos a todas las Administraciones que,

"No puede incluirse en la competencia exclusiva de autoorganización de las Comunidades Autónomas; aunque ciertamente, (... no cabe atribuir a las bases estatales la misma extensión e intensidad cuando se refieren a aspectos meramente organizativos internos que no afectan directamente a la actividad externa de la Administración y a los administrados, que en aquellos aspectos en los que se da esta afectación" (STC 50/1999, FJ 3). ${ }^{21}$ E incluso la propia doctrina del Constitucional sobre "lo básico", se ha llegado a proyectar sobre los propios aledaños de la regulación concreta y en todo aquello que preserve la existencia de la figura o concepto regulado: "Todo aquello que sea preciso para la preservación de la normativa de una institución considerada como básica, debe ser entendido asimismo como básico por vía de consecuencia o de conexión. De esta manera, si hemos considerado que es básica en el ordenamiento jurídico vigente la existencia de un cuerpo de funcionarios de alta cualificación, tiene que ser cierto que ha de poseer la misma connotación todo aquello que preserve la existencia de ese cuerpo y ello permitirá proscribir lo que lo haga desaparecer o lo menoscabe 22 ".

En segundo término, porque es inherente a la competencia atribuida por el art. 90.2 de la LRBRL al Estado la cualidad de regular de forma básica el régimen de las relaciones de puestos de trabajo en el ámbito local, que ejercerá dichas competencias de forma análoga a como lo ha hecho en su propio ámbito, sabiendo que "la técnica utilizada por la Constitución es compleja, dada la coincidencia sobre una misma materia de intereses generales de diverso alcance, y dado que un mismo objeto es susceptible -generalmente e ser situado en diversos campos. De aquí que para solucionar las cuestiones que puedan plantearse hay que partir del contenido inherente a cada competencia y sólo si, aun aplicado este criterio, se sigue produciendo un entrecruzamiento habrá que determinar la competencia que debe prevalecer 23 " que, en este caso, por afectar al conjunto de las Administraciones locales del Estado debe prevalecer la acción Estatal. Cuestión que la jurisprudencia del Tribunal Supremo también ha avalado, al dar un contenido básico al art. 15 de la Ley 30/1984: "Pues bien, como se sostiene en la sentencia recurrida el artículo 90.2 de la Ley Reguladora de las Bases de Régimen Local dispone que las Corporaciones locales formarán la relación de todos los puestos de trabajo existentes en su organización, en los términos previstos en la legislación básica sobre función pública. De aquí se deduce la aplicación del artículo 15 de la Ley 30/1984, aun referido a la "Relaciones de puestos de trabajo de la Administración del Estado", ante la falta de desarrollo del párrafo segundo del artículo 90.2 de dicha ley Reguladora de las Bases de Régimen Local, que prevé que corresponde al Estado establecer las

\footnotetext{
17 STC, del 23 de diciembre de 1993 (ROJ STC 385/1993). Recursos núms. 826/86, 839/86 y 842/86.

18 STC, del 4 de julio de 1991 (ROJ: STC 147/1991). Conflictos competencia acumulados núms. 384/85, 407/85 y 340/89.

19 STC, del 11 de diciembre de 1986 (ROJ: STC 158/1986) Conflicto competencia núm. 427/84.

20 STC, del 15 de septiembre de 1988 (ROJ STC 158/1988) Conflicto competencia núm. 1.233/86.

21 STC, del 4 de junio de 2013 (ROJ: STC 130/2013). Recurso. núm. 931/2004

22 STC, del 5 de octubre de 2000 (ROJ: STC 235/2000). Recursos acumulados núms. 830/92 y $2351 / 93$.

23 STC, del 22 de diciembre de 1981 (ROJ: STC 42/1981) Recurso núm. 221/81.
} 
normas con arreglo a las cuales hayan de confeccionarse las relaciones de puestos de trabajo, la descripción de puestos de trabajo tipo y las condiciones requeridas para su creación ${ }^{24}$.

En tercer lugar, porque su contenido está directamente vinculado al régimen estatutario de los funcionarios públicos y sus contenidos estructurales: provisión de puestos de trabajo, movilidad, retribuciones básicas y complementarias asignadas a los puestos y requisitos de desempeño que, por otro lado, son determinados como básicos, ex art. 16 de la Ley 30/1984, como también son citados por el art. 74 del EBEP: “la denominación de los puestos, los grupos de clasificación profesional, los cuerpos o escalas, en su caso, a que estén adscritos, los sistemas de provisión y las retribuciones complementarias". Es decir que dichas normas hacen "desenvolverse la condición de funcionario y ordenando su posición propia en el seno de la Administración"25".

Por tanto, hemos de entender que existe un contenido básico evidente que, por sí, hacen que sean aplicables a las organizaciones municipales, tanto la Orden de 2 de diciembre de 1988, sobre Relaciones de puestos de Trabajo $^{26}$ como la Orden de 6 de febrero de 1989 por la que se dispone la publicación de la Resolución conjunta de las Secretarías de Estado de Hacienda y para la Administración Pública por la que se aprueba el modelo de relaciones de puestos de trabajo de personal funcionario y se dictan normas para su elaboración ${ }^{27}$; y que ambas estarían incluidas dentro de la "legislación estatal que resulte de aplicación" a la que hace mención el art. 3.1 del EBEP. La posición central de de la legislación básica estatal o como dice también la LRBRL en el art. 92.1 "por la restante legislación del Estado en materia de función pública ${ }^{28}$ " adquiere mayor relevancia, si cabe, en nuestra materia dadas la remisiones automáticas que la propia legislación autonómica realiza sobre las RPTs, sabiendo que es la última posición que el EBEP reserva en el sistema de prelación de fuentes reguladoras de la materia (ex art. 3.1 EBEP). Así, por ejemplo, la Ley 7/1999, de 9 de abril, de Administración Local de Aragón, señala que "las Corporaciones locales formarán y aprobarán la relación de puestos de trabajo existentes en su organización, de acuerdo con la legislación básica de funcionarios de las Administraciones públicas y de la legislación de función pública de la Comunidad Autónoma. En la misma deberán incluirse, en todo caso, la denominación, características esenciales de los puestos, retribuciones complementarias que le correspondan y requisitos exigidos para su ejercicio ${ }^{29}$ ". Misma posición de reenvío que señala la Ley de Administración Local de la Comunidad de Madrid ${ }^{30}$, la Ley de la Administración Local de La Rioja ${ }^{31}$ y la Ley Municipal y de Régimen Local de Cataluña ${ }^{32}$. Otro tanto podemos decir de aquellas leyes autonómicas de régimen local que, aun no legislando sobre relaciones de puestos de trabajo, vienen a remitirse igualmente a la legislación básica Estatal. Este es el caso de la Ley de la Generalitat, de Régimen Local de la Comunitat Valenciana cuando afirma que "el régimen jurídico de los empleados públicos al servicio de la administración local que no sean habilitados de carácter estatal, se regirá por lo dispuesto en la legislación básica, en la Ley de Función Pública de la Generalitat y su desarrollo reglamentario 33 o la propia Ley, municipal y de régimen local de las Illes Balears ${ }^{34 "}$. A pesar de esto, consideramos positiva esta indefinición autonómica en relación con el ejercicio de las competencias locales, sobre todo teniendo en cuenta lo apuntado por FUENTETAJA PASTOR respecto a las leyes de función pública autonómicas y su poco o nada carácter respetuoso respecto a la necesidad de reconocer ámbitos o márgenes de actuación normativa o ejecutiva a las Entidades Locales ${ }^{35}$.

Así pues, ha de destacarse un papel especial que cabe a la actividad legislativa y normativa del Estado en esta materia de determinación del régimen jurídico de las "relaciones de puestos de trabajo u otros instrumentos organizativos similares", no solamente resolviendo -como hemos propuesto- la grave desatención normativa en el momento presente sino por la actividad que deba acometerse en un futuro próximo, y sobre todo por la "cuota" que deba darse a las propias potestades normativas municipales dado el carácter "bifronte" que estos instrumentos normativos tienen. Y esto último porque las RPTs tienen un papel singular, dentro del ámbito de la gestión y planificación de los recursos humanos y, por otro, como elementos configuradores de la organización administrativa municipal.

\footnotetext{
24 STS, contencioso sección 7, de 20 de octubre de 2008 (ROJ: STS 5629/2008). № de Recurso: 6078/2004.

25 STC, del 11 de Junio del 1987 (ROJ: STC 99/1987) Recurso: 763/1984.

26 BOE núm. 294, de 8 de diciembre de 1988.

27 BOE núm. 32, de 7 de febrero de 1989

28 La disposición, de notable imprecisión, que puede revelar un error conceptual en cuanto a la concepción de las características de la legislación básica y su función delimitadora entre ámbitos competenciales Estatales y Autonómicos, hubiera sido deseable que señalara algún criterio o materia de referencia de esta legislación

29 Art. 236.2 de la Ley 7/1999, de 9 de abril, de Administración Local de Aragón

30 Art. 105.1 de la Ley 2/2003, de 11 de marzo, de Administración Local de la Comunidad de Madrid

31 Art. 232.2 de la Ley $1 / 2003$, de 3 de marzo, de la Administración Local de La Rioja

32 Art. 291.2 de la Ley 8/1987, de 15 de abril, Municipal y de Régimen Local de Cataluña, cuyo tener literal es “Los Entes locales formarán la relación de puestos de trabajo de su organización, de conformidad con la legislación básica del Estado y con el desarrollo reglamentario de la

33 Art. 159.3 de la LEY 8/2010, de 23 de junio, de la Generalitat, de Régimen Local de la Comunitat Valenciana

34 Art. 190 de la Ley 20/2006, de 15 de diciembre, municipal y de régimen local de las Illes Balears.

35 Fuentetaja Pastor, Jesús Ángel “op. Cit.” Pág. 429 y 430.
} Generalidad" 


\section{3 Relaciones de puestos de trabajo y estatuto formal de los funcionarios locales}

El EBEP (art. 74) establece que las relaciones de puestos de trabajo u otros instrumentos organizativos similares, comprenderán, al menos, la denominación de los puestos, los grupos de clasificación profesional, los cuerpos o escalas, en su caso, a que estén adscritos, los sistemas de provisión y las retribuciones complementarias. Es evidente que el conjunto de elementos constitutivos de las RPT contienen en sí mismas los elementos básicos del estatuto de los funcionarios locales -comunes, por otro lado, a los restantes funcionarios- y que el Tribunal Constitucional ya destacara en la emblemática sentencia STC 99/1987: las condiciones de promoción en la carrera administrativa, al modo de provisión de puestos de trabajo al servicio de las administraciones publicas ya que "las normas que disciplinen estos ámbitos serán, en el concepto constitucional, ordenadoras del estatuto de los funcionarios públicos, pues todas ellas interesaran directamente a las relaciones entre estos y las administraciones a las que sirven, configurando así el régimen jurídico en el que pueda nacer y desenvolverse la condición de funcionario y ordenando su posición propia en el seno de la administración". Todas y cada una de éstas se posibilitan a través de las RPT, de tal manera que se convierte en el instrumento clave de la carrera profesional del funcionario y de su propia movilidad interadministrativa. Ha de tenerse en cuenta que las RPT, sea cual sea la estructura administrativa de la Administración local /municipal correspondiente, es una apuesta por un modelo de carrera profesional.

Efectivamente, como señala GUTIÉRREZ REÑON el sistema de carrera responde a una concepción más elaborada de la Función Pública. Parte de la base de que los funcionarios van a prestar sus servicios a la Administración durante toda su vida activa. A lo largo de ella no van a permanecer en un mismo puesto, sino que van a desempeñar una serie de puestos diferentes ${ }^{36}$. De hecho la doctrina del Tribunal Constitucional al respecto recalca el importante papel de las RPT a la hora de definir concretamente el desempeño y responsabilidades de cada puesto de trabajo que es el centro de la carrera administrativa: "La definición de este concreto concepto retributivo -se refiere al complemento específico, necesariamente presente en las RPT- está estrechamente relacionada con las decisiones fundamentales concernientes al propio modelo de función pública que descansa en el sistema de puestos de trabajo por el que optó el legislador estatal de la citada Ley 30/1984. Así es: la voluntad del legislador de alejarse de un sistema de estructura corporativa y de avanzar, en consecuencia, hacia un sistema abierto, mediante la implantación de la clasificación de los puestos de trabajo como "base sobre la que ha de articularse la auténtica carrera administrativa" (Exposición de Motivos de la Ley 30/1984), determinó la paralela modificación del anterior régimen retributivo. (...) De ahí que el complemento específico que nos ocupa, en la medida en que está derechamente orientado a "retribuir las condiciones particulares de algunos puestos de trabajo37". Y que, nuevamente, viene a recalcar la importancia del puesto sobre la carrera administrativa: "los difusos parámetros definidores del complemento específico quedan objetivados si mediante una actividad administrativa del órgano competente se hace la valoración de las respectivas relaciones de puestos de trabajo, de modo que resulta una auténtica catalogación por el orden de importancia de los distintos puestos para, en función de la misma, determinar la retribución económica a cargo del citado complemento específico ${ }^{38 "}$. De esta manera, el estatuto de los funcionarios se reconduce hacia el sistema de empleo que acapara el protagonismo de la función pública a través de las RPT que son la traducción técnica en nuestro derecho de las "Jobs descriptions" norteamericano39. Por tanto, la adquisición de derechos y su consolidación por parte de los funcionarios locales pasa por el desempaño del puesto /s en la RPT, sabiendo, no obstante, que no existe, por ejemplo, un derecho de los funcionarios a la movilidad, sino una posibilidad de movilidad condicionada a las relaciones de puestos de trabajo de las Administraciones de destino. Las RPT actualizan y concretan el conjunto de normas estatuarias reguladoras de la relación jurídica del funcionario con la Administración para posibilitar su inserción en la organización correspondiente y en su propia carrera administrativa. A este respecto ha de tenerse en cuenta que el fortalecimiento de la carrera administrativa en los funcionarios locales propios son el mejor bálsamo para alejar a éstos y la prestación del servicio público, de las intromisiones políticas ${ }^{40}$.

Pero estas facultades administrativas respecto de sus propios recursos humanos, tienen también sus límites y las RPT no pueden crear elementos de exclusión sobre fundamentos apodícticos y sin una motivación convincente basada en la realidad de sus efectivos y en el modelo adoptado. La vulneración de la razonabilidad administrativa en esta materia es puesta de manifiesto por el propio Tribunal Constitucional al afirmar sobre un caso concreto de exclusión en el desempeño de puestos de trabajo por una supuesta inidoneidad: "en efecto, que en aplicación de la exclusión prevista en la relación de puestos de trabajo para los puestos convocados, en la que se justifica

36 Gutiérrez Reñón, Alberto (1987) “La carrera administrativa en España: histórica y perspectivas”. Documentación Administrativa. Núms. 201-211. Pág. 66.

37 STC, del 22 de mayo de 1997 (ROJ: STC 103/1997). Recurso núm. 544/88.

38 STC, del 29 de noviembre de 1993. (ROJ: STC 357/1993. Recurso núm. 2.113/91.

39 Sánchez Morón, Miguel (2000) “Derecho de la función Pública”. $2^{\circ}$ edición -reimpresión-. Ed. Técnos. Madrid. Pág. 111.

40 "En la mayoría de los países de Europa, con unas u otras peculiaridades, existen sistemas de carrera administrativa encaminados fundamentalmente a conseguir una Función Pública profesionalizada, con estabilidad frente a los cambios de gobierno y neutral políticamente" en Álvarez Álvarez, Julián "Neutralidad política y carrera administrativa de los funcionarios públicos” Documentación Administrativa-1987, núms. 210-211. Pág. 78 
dicha exclusión con fundamento en que resultan ajenos absolutamente a las funciones de gestión administrativa, las Órdenes impugnadas impidan a los miembros de determinados cuerpos de funcionarios concursar a los puestos convocados es contrario al art. 23.2 CE. Ello implica una presunción de la inidoneidad para el desempeño de la función por parte de funcionarios, respecto de los que, por su mera pertenencia a un cuerpo, no se puede afirmar a priori que no vayan a contar necesariamente con las condiciones para su óptimo desarrollo, ya que no puede considerarse razonablemente justificado la exclusión de un colectivo como los funcionarios docentes, tanto si se analiza desde la perspectiva puramente de gestión, ya que existen docentes en ramas especializadas de gestión de las Administraciones públicas, como desde la perspectiva de la materia a gestionar, porque existen variedad de titulaciones académicas en las que la protección del medio ambiente constituye el núcleo de la formación ${ }^{41}$ ". Algo que vuelve a recordarse en una sentencia posterior: "en efecto, la STC 48/1998 concluyó que supone una vulneración del art. 23.2 CE la exclusión a limine de determinados cuerpos de funcionarios de los concursos de provisión para determinados puestos de la Administración, en tanto que ello establece una presunción de la inidoneidad para el desempeño de la función de personas en las que podrían concurrir las condiciones necesarias para su óptimo desarrollo (FFJJ 7 y 8) ${ }^{42 "}$. Lo cual significa que la RPT puede incurrir en arbitrariedad, como señala la jurisprudencia del Tribunal Supremo, "en efecto, la Relación de Puestos de Trabajo es un instrumento de ordenación del personal que la Ley ofrece a las Administraciones Públicas para que con ella establezcan la estructura o diseño de los mismos y los requisitos necesarios para su desempeño. Es, pues, una manifestación de la potestad de organización de la que disfruta y, como ésta, debe respetar, entre otros, el principio de interdicción de la arbitrariedad al clasificar esos puestos ${ }^{43}$ ". Si, por ejemplo no se motivara de forma clara la modificación de los puestos de trabajo se incurriría en arbitrariedad tal y como ha reiterado una abundante doctrina jurisprudencial sobre este cuestión: "las facultades de gestión de su personal, que puede llevar a cabo mediante el instrumento que representa la Relación de Puestos de Trabajo; sin embargo, esa potestad de autoorganización no le autoriza para tomar decisiones que restrinjan los derechos de los funcionarios si no media su justificación mediante una motivación suficiente que satisfaga las exigencias del principio de interdicción de la arbitrariedad proclamado por el artículo 9.3 de la Constitución44". Consideraciones que, incluso, se hacen extensibles, según el propio Tribunal Supremo, a la asignación de niveles dentro de la estructura, en función de la valoración de los puestos: "Éstas [las relaciones de puestos de trabajo] contienen la estructura y valoración de los puestos de trabajo, como en el caso enjuiciado por la sentencia recurrida, donde lo único que se recurre es la valoración que se da a un funcionario por la citada Relación, estimando que conlleva una discriminación , y en consecuencia restaurando el derecho fundamental del recurrente ${ }^{45}$ " Así pues, ciertos derechos de los funcionarios, que pasan por el reconocimiento de los adquiridos a través de la carrera administrativa, han de contemplarse en la propias RPT. Y que desde luego van más allá de lo establecido por el Texto Refundido de Régimen Local cuando establecía "el derecho al cargo, sin perjuicio de su adscripción a unos u otros puestos de trabajo, efectuada dentro de sus competencias respectivas por los distintos órganos competentes en materia de funcionarios públicos locales 46 ". Aunque es perfectamente admisible que puedan existir "diferencias de tratamiento durante el periodo transitorio en el que se procede a la plena integración de los trabajadores transferidos en las estructuras de la nueva Administración de la que dependen, perdiendo sin embargo sentido en un momento posterior, esto es, a partir de que se ha perfeccionado la asimilación del personal (como sucedía en el supuesto analizado por la STC 110/2004, de 30 de junio). Esto es, sólo una vez consolidado el proceso existirá identidad de situaciones entre transferidos y personal propio de la Administración receptora, y deberán aplicarse idénticas condiciones económicas y laborales a quienes ocupen los mismos puestos de trabajo, independientemente de la Administración de origen47”.

Aspecto capital dentro de la carrera administrativa, y consecuencia del propio estatuto de los funcionarios, es la expectativa de movilidad que genera el desempeño del puesto ya que los empleados públicos tienen derecho al desempeño de un puesto de trabajo de acuerdo con el sistema de estructuración del empleo público que establezcan las leyes de desarrollo del EBEP48. Es más, la movilidad se ha constituido en un elemento básico de la carrera administrativa desde la introducción del puesto de trabajo en detrimento de la pertenencia al Cuerpo

41 STC del 4 de junio de 2007 (ROJ: STC 129/2007). Recurso núm. 1266/2003.

42 STC del 13 de octubre de 2008 (ROJ: STC 118/2008). Recurso núm. 8822/2006.

43 STS, contencioso sección 7, del 15 de octubre de 2012 (ROJ: STS 7411/2012). N de Recurso: 4067/2011.

44 STS, contencioso sección 7, del 21 de noviembre de 2012 (ROJ: STS 8023/2012) N de Recurso: $2579 / 2011$.

45 STS, contencioso sección 7, del 20 de octubre de 2008 (ROJ: STS 5742/2008). N de Recurso: $6601 / 2004$.

46 Art. 141del Real Decreto Legislativo 781/1986, de 18 de abril, por el que se aprueba el Texto Refundido de las disposiciones legales vigentes en materia de Régimen Local

47 STC, del 15 de diciembre de 2005 (ROJ: STC 330/2005) Rec. núm. 2177/98

48 Art. 73.1 de la Ley 7/2007, de 12 de abril, del Estatuto Básico del Empleado Público. 
y su desagregación en categorías". En efecto, "la movilidad de funcionarios entre las distintas Administraciones Públicas y, en concreto, entre funcionarios de las Administraciones Autonómicas y la del Estado, que es el supuesto que ahora interesa, se encuentra regulada en el art. 17.1 de la Ley 30/1984 de Medidas para la Reforma de la Función Pública $^{50}$; norma que, si bien parte de la consideración de que la movilidad puede contribuir a una mejor utilización de los recursos humanos, hace depender esta posibilidad de lo que dispongan las relaciones de puestos de trabajo. En definitiva, deja que sea cada una de las Administraciones Públicas las que, a través de las Relaciones de Puestos de Trabajo, determine los puestos que pueden ser desempeñados por funcionarios de otras Administraciones Públicas ${ }^{51}$ ". Algo que también ha sido admitido por la jurisprudencia del Tribunal Supremo: "y que es la Relación de Puestos de Trabajo la que ha de efectuar expresamente tal previsión de movilidad interadministrativa para que sea efectiva e integrar dentro de su estatuto el derecho de los funcionarios a tal movilidad52". Otorgando la jurisprudencia del Tribunal Supremo, a las RPT, la garantía de esta propia carrera profesional cuando, por ejemplo, "ha dejado de tener en el funcionario afectado la confianza ínsita a la libre designación, ha de proveer, de pretender hacer uso de su libertad de destitución, a la inclusión en la correspondiente relación de puestos de trabajo de uno con contenido idéntico a aquél en el cual se ha producido el cese, mas (porque lo contrario implicaría llevar la contradicción hasta su último extremo) con una responsabilidad diferente, de donde, en el oportuno desarrollo reglamentario (art. 28, párrafo segundo, del Real Decreto 731/1993, dictado, según se dijo, para acomodar el Real Decreto 1174/1987 a las previsiones de la Ley de reforma del art. 99 LBRL53". Aunque también se reafirma por aquélla que "en el régimen estatutario de las relaciones funcionariales no existen derechos adquiridos en relación con el mantenimiento del régimen vigente en cada momento, sino que el status funcionarial será el que se derive de su norma rectora, la cual se halla bajo la disponibilidad del legislador o del titular de la potestad reglamentaria54".

Añádase además que los Textos legislativos locales se cuidan de asociar otro elemento básico del estatuto de los funcionarios, como es el ingreso en la función pública, al desempeño del puesto teniendo en cuenta la menor importancia que el Cuerpo ha tenido en el ámbito local, ya que la agrupación de funcionarios locales propios de estas Corporaciones a través de escalas y subescalas de Administración General y Administración Especial, priman el desempeño del puesto sobre el grupo funcionarial de pertenencia. Así es, ya que el procedimiento de selección de los funcionarios de Administración local además de ajustarse a la legislación básica del Estado sobre función pública, ha de tener en cuenta especialmente la conexión entre el tipo de pruebas a superar y la adecuación a los puestos de trabajo que se hayan de desempeñar, incluyendo a tal efecto las pruebas prácticas que fueren precisas 55 .

Por lo tanto, las RPT constituyen la plasmación del conjunto normativo del que forma parte el estatuto de los funcionarios públicos y el fundamento de su movilidad, y carrera administrativa, especialmente en el ámbito local, en donde las posibilidades de carrera y promoción pasan por la propia dimensión de su estructura administrativa y la plantilla que ha de hacer frente a dichas tareas. Plasmación que contiene todas las garantías jurídicas de una norma administrativa de carácter reglamentario indudable aunque sobre esta cuestión hablaremos más tarde.

\section{OTROS INSTRUMENTOS DE ORDENACIÓN DE LOS EMPLEADOS PÚBLICOS, PREVIOS O CONJUNTOS, CON LAS RELACIONES DE PUESTOS DE TRABAJO EN LAS ADMINISTRACIONES LOCALES}

La LRBRL establece que corresponde a cada Corporación local aprobar anualmente, a través del Presupuesto, la plantilla, que deberá comprender todos los puestos de trabajo reservados a funcionarios, personal laboral y eventual. Las plantillas deberán responder a los principios de racionalidad, economía y eficiencia y establecerse de acuerdo con la ordenación general de la economía, sin que los gastos de personal puedan rebasar los límites que se fijen con carácter general ${ }^{56}$, disposición que se ve complementada por el Texto Refundido al señalar que

49 Arts. 23 y 28 del Decreto 315/1964, de 7 de febrero, por el que se aprueba el texto articulado de la Ley de Funcionarios Civiles del Estado. A este respecto PARADA VÁZQUEZ señala que la Ley de funcionarios civiles de 1964, al desvirtuar el sistema de cuerpos de funcionarios, por influencia anglosajona, por la supresión de las categorías intracorporativas, igualó a todos los funcionarios de un mismo cuerpo al efecto de ejercer desde las más modestas funciones del mismo hasta las más altas y directivas e introdujo en compensación el instrumento de clasificación de puestos de trabajo”, en “Derecho del Empleo Público. La la Ley $7 / 2007$, de 12 de abril, del Estatuto Básico del Empleado Público". Ed. Marcial Pons. Madrid. 2007. Pág. 128.

50 El art. 17.1 de la Ley 30/1984, de 2 de agosto, de medidas para la reforma de la Función Pública establece que los funcionarios de la Administración local, cuando así esté previsto en las relaciones de puestos de trabajo, podrán desempeñar puestos de trabajo en otras Corporaciones locales, en las Administraciones de las Comunidades Autónomas y en la Administración General del Estado en puestos relacionados con las funciones que les competen en materia de Entidades locales. Lo cual supone una limitación poco justificable dado que las funciones administrativas emanan del conjunto de leyes administrativas comunes a todas las Administraciones públicas.

51 STC, del 13 de julio de 1998, (ROJ: STC 156/1998). Recurso núm. 3.455/95.

52 STS, contencioso sección 7, del 8 de octubre de 2012 (ROJ: STS 7829/2012) Nº de Recurso: 1914/2011.

53 STC, del 5 de octubre de 2000 (ROJ: STC 235/2000). Recursos núms. 830/92 y 2351/93.

54 STS, contencioso sección 7, del 21 de noviembre de 2012 (ROJ: STS 8023/2012) N de Recurso: $2579 / 2011$.

55 Art. 133 del Real Decreto Legislativo 781/1986, de 18 de abril, por el que se aprueba el Texto Refundido de las disposiciones legales vigentes en materia de Régimen Local

56 Art. 90.1 de la Ley 7/1985, de 2 de abril, reguladora de las Bases del Régimen Local 
las plantillas, las cuales deben comprender todos los puestos de trabajo debidamente clasificados reservados a funcionarios, personal laboral y eventual, se aprobarán anualmente con ocasión de la aprobación del Presupuesto y habrán de responder a los principios antes enunciados. A ellas se unirán los antecedentes, estudios y documentos acreditativos de que se ajustan a los mencionados principios ${ }^{57}$. Disposiciones a las que añadiremos las del Real Decreto 861/1986, de 25 de abril, por el que se establece el régimen de las retribuciones de los Funcionarios de Administración Local, cuyo contenido básico hace ineludible su cumplimiento por parte de las corporaciones locales ${ }^{58}$ y porque obedece al desarrollo de la previsión contenida en el art. 90.2 de la LRBRL, al determinarse que corresponde al Estado establecer las normas con arreglo a las cuales hayan de confeccionarse las relaciones de puestos de trabajo, la descripción de puestos de trabajo tipo y las condiciones requeridas para su creación, así como las normas básicas de la carrera administrativa, especialmente por lo que se refiere a la promoción de los funcionarios a niveles y grupos superiores.

Así pues, junto a las relaciones de puestos de trabajo nos encontramos con la siguiente tipología de instrumentos que las "rodean", bien como elementos constitutivos, bien como elementos preparatorios, e incluso como documentos complementarios de éstas: las denominadas plantillas orgánicas, los puestos de trabajo - tipo o catálogos de puestos de trabajo, la valoración de los puestos de trabajo y los presupuestos de la entidad local en cuanto acto de dotación económico -presupuestaria de aquéllos.

\subsection{Instrumentos de carácter previo: Catálogos de puestos de trabajo}

Hemos de entender como catálogo de puestos de trabajo el conjunto de puestos agrupados conforme a una tipología funcional emanada de su pertenencia a un grupo funcionarial de titulación determinada, su pertenencia a un Cuerpo o Escala, su inserción orgánica administrativa a través del puesto, y los niveles retributivos que reflejen dichas responsabilidades. La inexactitud técnica en las normas reguladoras es llamativa teniendo en cuenta que la ley determina su creación previamente a la aprobación de las relaciones de puestos de trabajo porque el puesto es un elemento básico en la estructura de la función pública española y porque el funcionario de nuevo ingreso debe acceder a un puesto que en el caso de la no existencia de la RPT, debe ser proporcionado por el catálogo de puestos existente en ese momento.

La primera mención normativa referida a los catálogos de puestos de trabajo la encontramos en la Ley de Presupuestos Generales del Estado del año 1986 y se determinan como la enumeración de los puestos de trabajo de cada Centro Gestor, con expresión de: a) El nivel de complemento de destino y, en su caso, del complemento específico que corresponden a los mismos, cuando hayan de ser desempeñados por personal funcionario. b) La categoría profesional y régimen jurídico aplicable, cuando hayan de ser desempeñados por personal laboral, significándose una cuestión que también ha sido traspasada a las relaciones de puestos de trabajo, y es que los créditos de gastos de personal no implicarán, en ningún caso, reconocimiento de derechos ni modificación de los catálogos de puestos de trabajo, ni éstos, a su vez, condicionarán necesariamente la cuantía de los citados créditos ${ }^{59}$. Es decir, que no es un instrumento básico, podríamos decir, de impacto presupuestario, sino que el capítulo de gastos de personal de los presupuestos de gastos de cada Administración predetermina su efectividad sobre el número real de efectivos de cada centro gestor o administración municipal concreta. Cuestión ésta que ha sido recogida por la propia jurisprudencia, que se hace eco, al mismo tiempo, de las contradicciones actualmente existentes sobre la normativa básica de los funcionarios públicos tras la entrada en vigor del EBEP: "De otro lado, es cierto que ésta y la plantilla no coinciden pues su objeto es diferente y puede la primera contemplar puestos que no aparecen en la segunda por no haber sido dotados. Y, también, es verdad que el artículo 15 de la Ley 30/1984 se refiere a la Administración del Estado. (...) Por lo demás, el artículo 16, siempre de la Ley 30/1984, éste sí dirigido a las Administraciones autonómicas y locales, ha sido derogado por el Estatuto Básico del Empleado Público, cuyo artículo 74 deja a las Administraciones Públicas la determinación de los concretos contenidos de sus relaciones de puestos de trabajo, si bien el vigente artículo 1.3 de la Ley 30/1984 lo incluye entre las bases del régimen estatutario de los funcionarios públicos aplicable al personal de todas las Administraciones Públicas ${ }^{60 "}$. Y se vuelve a reiterar que la creación, modificación, refundición o supresión de los puestos de trabajo en las unidades orgánicas, se realizará a través de los catálogos de puestos de trabajo, sin perjuicio de que mediante las respectivas normas sobre organización administrativa se puedan determinar las unidades, sus competencias, funciones y asignación de tareas, sin que ello condicione en ningún caso el número de dotaciones y las características retributivas

57 Art. 126 del Real Decreto Legislativo 781/1986, de 18 de abril, por el que se aprueba el Texto Refundido de las disposiciones legales vigentes en materia de Régimen Local

58 En concreto se trata de la Disposición Transitoria segunda del citado Real Decreto: "hasta tanto se dicten por la Administración del Estado las normas con arreglo a las cuales hayan de confeccionarse las relaciones de puestos de trabajo, la descripción de puestos de trabajotipo y las condiciones requeridas para su creación, los Plenos de las Corporaciones Locales deberán aprobar un catálogo de puestos a efectos de complemento específico. Mientras no estén aprobadas tales normas, los catálogos únicamente podrán ser modificados mediante acuerdo del Pleno".

59 Art. 23 de la Ley 46/1985, de 27 de diciembre, de Presupuestos Generales del Estado para 1986.

60 STS, contencioso sección 7, del 25 de junio de 2012 (ROJ: STS 5470/2012) Nº de Recurso: 2583/2011. 
reflejadas en el correspondiente catálogo. Finalmente se específica que corresponde al Gobierno, a propuesta del Ministerio de Economía y Hacienda, la aprobación de los catálogos de la Administración del Estado y sus Organismos autónomos correspondientes a la aplicación inicial del régimen retributivo previsto en la propia ley de presupuestos ya que, además, ha de servir como norma de referencia para aplicar el nuevo régimen retributivo generado por la Ley 30/1984 con caracteres básicos ampliamente reconocidos por la jurisprudencia ordinaria y constitucional $^{61}$. De igual forma se diseña un procedimiento para su modificación.

Sin embargo, las Leyes de Presupuestos Generales del Estado (PGE) para ejercicios siguientes vuelven a señalar, a los catálogos de puestos de trabajo, como elemento transitorio para la definitiva configuración de las estructuras administrativas y de personal de los diferentes Centros Gestores ${ }^{62}$. Que vienen a ser representadas por las RPT: "hasta tanto se aprueben las relaciones de puestos de trabajo de la Administración del Estado y sus Organismos Autónomos, se mantendrán en vigor los catálogos de puestos de trabajo aprobados a la entrada en vigor de la presente Ley ${ }^{63}$ "; contenido que, nuevamente, se reproduce en las siguientes leyes de presupuestos, incluso con el mismo tenor literal, hasta la Ley de Presupuestos Generales del Estado para el año 1994. Los preceptos mencionados añaden un sistema propio para su modificación, que ya fuera regulado para la Ley de presupuestos de 1989: las modificaciones se efectuarán conforme al procedimiento señalado en el artículo 37 de la Ley 37/1988, que curiosamente se refiere al procedimiento de modificación de las RPT. Ciertamente que hemos de calificar dicha reiteración como un producto típico de la inercia legislativa.

El traslado al ámbito local de los catálogos, al margen de su propio contenido básico, que también lo tienen, según hemos expuesto más arriba, se realiza a través del Real Decreto 861/1986, de 25 de abril, por el que se establece el régimen de las retribuciones de los Funcionarios de Administración Local, con el mismo carácter de transitoriedad que se le otorga a los catálogos de puestos de trabajo del Estado: "hasta tanto se dicten por la Administración del Estado las normas con arreglo a las cuales hayan de confeccionarse las relaciones de puestos de trabajo, la descripción de puestos de trabajo-tipo y las condiciones requeridas para su creación, los Plenos de las Corporaciones Locales deberán aprobar un catálogo de puestos a efectos de complemento específico. Mientras no estén aprobadas tales normas, los catálogos únicamente podrán ser modificados mediante acuerdo del Pleno ${ }^{64 "}$. En efecto, la medida explicitada en el preámbulo de la norma, aunque con un mayor carácter presupuestario que de ordenador de los recursos humanos, se enmarcaba dentro de la concesión de un plazo prudencial --que debería extenderse a lo largo de todo el año 1986-- con objeto de que las Corporaciones Locales pudieran realizar los estudios, adaptaciones y valoraciones de puestos de trabajo que sirvieran de base a una adecuada y eficaz implantación del nuevo sistema, sin que su aplicación permita superar los límites de incremento de la masa retributiva establecidos con carácter general. El hecho es que el Decreto añade más elementos de juicio sobre las relaciones de puestos de trabajo que sobre los propios catálogos, para los que es obligado dirigirse a los contenidos señalados en las leyes de Presupuestos Generales del Estado ya que parecen quedar asociados al establecimiento de los complementos específicos. La torpeza normativa o es casual o es causal porque la confusión ha reinado con cierta profusión en los ámbitos de las administraciones locales -aunque también estatales- que han llegado a identificar unos y otros elementos normativo dándoles, incluso, el mismo tratamiento. No obstante, la calificación de normas otorgada a los catálogos de puestos de trabajo, aspecto refrendado por la atribución al Pleno de su aprobación, es un dato clarificador de su naturaleza jurídica y también de las RPT.

La confusión sobre ambas figuras normativas se prodiga también en la jurisprudencia de Tribunal Supremo: "pero que no dictadas estas normas, no cabe equiparar el Catálogo General de Puestos de Trabajo de la Diputación a una Relación, por no cumplir aquél los requisitos que para las Relaciones prevé el artículo 16 de la Ley de la Función Pública. Recientemente, en sentencia de 13 de noviembre de 1995, hemos señalado que, al margen de la apariencia formal de la denominación utilizada, a un Catálogo se le puede dar el significado funcional de una relación de puestos de trabajo, en tanto se ajuste a la normativa básica reguladora de éstas, que en el ámbito de la Administración Local, al

61 La sentencia que ahora señalamos se detiene en la diferente técnica a emplear por los PGE en las subidas /congelaciones de los diferentes conceptos retributivos de los funcionarios cuyo carácter es básico per se: "Así, ciertamente, el criterio básico se materializa respecto del complemento de destino, concretando la cuantía que por tal concepto corresponde a cada nivel, desde el nivel 1 hasta el nivel 30 (art. 21.1.c). Pero esta técnica no se materializa así en relación con el complemento específico, lo que, sin duda, se deriva de la considerable extensión y complejidad de las diferentes relaciones de puestos de trabajo existentes en el seno de la Administración General del Estado y de sus diferentes organismos. De aquí que las Leyes de presupuestos generales del Estado suelan emplear una técnica diferente para determinar el porcentaje de subida de este complemento, técnica consistente en regular el porcentaje general de subida que procede, con las correcciones que, en su caso, hayan de aplicarse adicionalmente; en el caso que nos ocupa el criterio de congelación se concreta también de este modo (art. 21.1.d). En cuanto al complemento de productividad, la indeterminación en las leyes estatales es, lógicamente, mucho mayor aún y, en todo caso, alejada de la cuantificación exacta (art. 21.1.e)" STC del 6 de julio de 2006 (STC 222/2006). Recurso núm. 1298/97.

62 Con el término "Centros Gestores" viene introducirse un concepto netamente presupuestario en detrimento de un término, podríamos decir más" administrativo": los centros gestores, son aquellas unidades con diferenciación presupuestaria y con responsabilidad en la gestión de los programas presupuestarios para ello vid. Art. 6 de la Orden HAP/981/2013, de 31 de mayo, por la que se dictan las normas para la elaboración de los Presupuestos Generales del Estado para 2014 (BOE núm. 133, de 4 de junio de 2013 ).

63 Disposición Transitoria $9^{\text {a }}$ de la Ley 21/1986, de 23 de diciembre, de Presupuestos Generales del Estado para 1987.

64 Es la Disposición transitoria $2^{a}$. 
no haber sido promulgada la normativa básica prevista en el artículo 90-2 de la Ley 7/85, está constituida por el artículo 16 de la Ley 30/84 65". Y de la misma forma que para las RPT, el pronunciamiento jurisprudencial sobre su naturaleza jurídica añade más sombras que luces: "El defecto de orden formal denunciado por la parte actora, en cuanto aduce que el Acuerdo debió adoptar la forma del Real Decreto, en congruencia con lo establecido en el artículo 24 de la Ley de Régimen Jurídico , tampoco puede entenderse concurrente para acceder a la petición de nulidad formulada, pues la aprobación del catálogo de puestos de trabajo no reviste el carácter de disposición normativa de orden general, enderezada á disciplinar o regular genéricamente el nuevo régimen retributivo o a desarrollar reglamentariamente normas legales, sino que ha de ser calificado como acto administrativo plural, dictado en aplicación de las normas legales examinadas que bien pudo ser adoptado bajo la forma de Acuerdo, pues las leyes encomiendan al Gobierno su aprobación y el Gobierno está constituido por el Consejo de Ministros, debiendo por último señalarse que el Acuerdo recurrido no altera las normas organizativas, ya qué simplemente incorpora una relación de los puestos de trabajo económicamente dotados qué no excluye la existencia de aquellas, cual se reconoce en el artículo 23.2 de la Ley $46 / 1985^{66 " \prime}$.

Así pues, los catálogos de puestos de trabajo son disposiciones enteramente transitorias e, inicialmente, un producto necesario para la confección y aprobación de la relación de puestos de trabajo, pero normas, al fin y al cabo, porque ambas permanecen en el ordenamiento local respectivo y generan actos administrativos de aplicación. La semejanza de las disposiciones legislativas reguladoras entre una y otra, han hecho que con frecuencia se confundan, y en este defecto se han prodigado más las Administraciones locales. Es verdad que los catálogos son normas mediales respecto a las RPT y la implantación del nuevo régimen retributivo creado por la Ley de Medidas para la Reforma de la Función Pública, pero también completas en cuanto a sus consecuencias jurídicas, y son el primer instrumento para la regulación organizativa y de ordenación del personal que con posterioridad realizarán las RPT. Sin embargo, su finalidad es mayormente de ordenación y planificación de los recursos humanos asemejándose a las plantillas orgánicas aunque también se apunta su utilidad organizativa. La Ley de Presupuestos Generales del Estado para 1986, en su art. 23, establecía que correspondía al Gobierno, a propuesta del Ministerio de Economía y Hacienda, la aprobación de los catálogos de la Administración del Estado y sus Organismos autónomos correspondientes a la aplicación inicial del régimen retributivo previsto en el artículo trece de la Ley, el cual es el referido a las retribuciones básicas y complementarias aprobadas por el art. 21 de la Ley 30/1984 (artículo que, en la actualidad, ha sido sustituido por el art. 22 del EBEP). Catálogos resultantes que debían también contemplar la previsión de la Ley de Presupuestos Generales del Estado para 1985, que establecía que, con independencia de las retribuciones básicas y del complemento de destino, el Gobierno asignará un complemento específico a determinados puestos de trabajo, incluidos, en su caso, los Directores Generales, cuando dicha asignación sea necesaria para asegurar que la retribución total de cada puesto de trabajo guarde la relación adecuada con el contenido de especial dificultad técnica, dedicación, responsabilidad, peligrosidad o penosidad del mismo ${ }^{67}$.

No podemos sino reafirmar el carácter de norma respecto a los catálogos de puestos de Trabajo, primero porque se trata de un desarrollo directo del régimen retributivo diseñado por el art. 21 de la Ley 30/1984, que, en definitiva, aplicaba un sistema de función pública básico para todas las Administraciones públicas. En segundo lugar, porque se reúnen los requisitos propios de una norma reglamentaria al poseer los rasgos de generalidad, abstracción y permanencia -que no es lo mismo que tiempo indefinido-, y porque además se ha ejercicio el máximo grado de la discrecionalidad administrativa que es típico de toda norma jurídica. En tercer lugar, los catálogos, norman ámbitos organizativos Departamentales, dimanando directamente de los Decretos de organización de cada Departamento Ministerial, determinando las unidades, sus competencias, funciones y asignación de tareas, sin que ello condicione, en ningún caso, -como afirma la regulación de éstos- el número de dotaciones y las características retributivas reflejadas en el correspondiente catálogo. Lo cual, por otro lado, hace que se alejen en su caracterización de las plantillas orgánicas. La jurisprudencia fue oscilante -como posteriormente lo ha sido con las RPT- a la hora de reconocerles estos efectos normativos a los catálogos pasando desde su caracterización "como acto administrativo plural dictado en aplicación de las normas legales examinadas que bien pudo ser adoptado bajo la forma de Acuerdo ${ }^{68 "}$ " hasta su reconocimiento como tal norma dispositiva: "Deben reconocerse

65 STS, contencioso sección 7, del 23 de enero de 1997 (ROJ: STS 329/1997). Nº de Recurso: 10/1996.

66 STS, contencioso sección 1, del 28 de septiembre de 1987, (ROJ: STS 11576/1987) № de Recurso: $623 / 1986$.

67 Art. 11. 4 de la Ley 50/1984 de 30 de diciembre de Presupuestos Generales del Estado para el año 1985.

68 Efectivamente este es el sentido de la STS, contencioso sección 1, del 28 de septiembre de 1987, (ROJ: STS 11576/1987) N de Recurso: 623/1986: "tampoco puede entenderse concurrente para acceder a la petición de nulidad formulada, pues la aprobación del catálogo de puestos de trabajo no reviste el carácter de disposición normativa de orden general, enderezada á disciplinar o regular genéricamente el nuevo régimen retributivo o a desarrollar reglamentariamente normas legales, sino que ha de ser calificado como acto administrativo plural, dictado en aplicación de las normas legales examinadas que bien pudo ser adoptado bajo la forma de Acuerdo, pues las leyes encomiendan al Gobierno su aprobación y el Gobierno está constituido por el Consejo de Ministros, debiendo por último señalarse que el Acuerdo recurrido no altera las normas organizativas, ya qué simplemente incorpora una relación de los puestos de trabajo económicamente dotados qué no excluye la existencia de aquellas, cual se reconoce en el artículo 23.2 de la Ley 46/1985" 
las dificultades que en muchos casos entraña distinguir si un catálogo de puestos de trabajo es una disposición general o un acto administrativo plural, señalando a este respecto que el criterio que con carácter general se ha venido manteniendo por este Tribunal-Sentencias de 21 de diciembre de 1987, 10 de mayo de 1988, 20 de julio de 1990, 22 de enero de 1991, 5 de febrero de 1991, etc.- es el de tener en cuenta su contenido y vocación de permanencia, conjugando ambos factores, de forma que cuando el catálogo regula el régimen jurídico, organizativo, económico, etc., de los puestos de trabajo, y ese régimen se establece con vocación de permanencia, se considera que es una disposición general, (...) puesto que el acuerdo impugnado se limitaba a fijar los complementos de puestos de trabajo para el año 1985 , faltando en consecuencia los elementos que definen la naturaleza de las disposiciones generales ${ }^{69}$. Aunque jurisprudencia más reciente relativa a los catálogos --evidenciando cierta confusión conceptual con las RPT-- se abona a un concepto simplemente pragmático que, por otro lado, ha sido el resultado final también de la evolución de la propia jurisprudencia respecto de las RPT: "Atendida la obvia caracterización del objeto del proceso como cuestión de personal, la admisión del recurso de casación se justifica por la inclusión del mismo en el apartado 3 del artículo 93 de la Ley Jurisdiccional de 1956, en cuanto que, existe una impugnación indirecta del catálogo de puestos de trabajo, al que la jurisprudencia de la Sala viene reconociendo eficacia normativa, siquiera sea a los limitados efectos de admisión del recurso. Aceptado sobre esta base el acceso a la casación, la consecuencia inmediata es que el límite de ésta debe fijarse en el análisis de la validez del catálogo, excluyendo otras consideraciones, como las relativas a la supuesta extemporaneidad de la reclamación administrativa, cuya desestimación dio origen al proceso $\mathrm{70}^{70}$.

\subsection{Instrumentos adicionales: Plantillas orgánicas y presupuestos municipales}

Este concepto jurídico ha perdido el protagonismo que inicialmente le diera la Ley de Funcionarios Civiles del Estado de 1964 y el hecho de que ineludiblemente estuvieran unidas al "puesto de trabajo". Efectivamente, las plantillas orgánicas eran necesarias para instrumentar el proceso diseñado por el Texto articulado para la reforma de la Función pública española en aquél momento porque todos los Centros y dependencias de la Administración del Estado, debían crear y constituir sus correspondientes plantillas orgánicas, en las que se debían relacionar, debidamente clasificados, los puestos de trabajo de que constaran ${ }^{71}$. $\mathrm{Y}$, como ya hemos destacado más arriba, su naturaleza jurídica generó las mismas dudas que las RPT, dado que las plantillas orgánicas y sus modificaciones debían ser aprobadas por el Gobierno, previo informe de la Comisión Superior de Personal, y ser publicadas al fin de cada bienio en el «Boletín Oficial del Estado». De hecho, las plantillas orgánicas se convierten en elemento imprescindible e incluso caracterizador de la noción de funcionario de carrera que da la propia Ley: "Son funcionarios de carrera los que, en virtud de nombramiento legal desempeñan servicios de carácter permanente, figuran en las correspondientes plantillas..."

La Ley 30/1984, de 2 de agosto -con bastante poca precisión técnica- hace referencia a las plantillas, no orgánicas, sino a las plantillas de los diferentes Cuerpos y Escalas de la Administración del Estado, así como las del personal laboral, y que serán las que resulten de los créditos establecidos en la Ley de Presupuestos ${ }^{72}$, adelantando la verdadera función de este concepto que no es otro que prefijar el estado de gastos dedicados al personal por los presupuestos anuales de las distintas Administraciones públicas e incluso a formar parte de estos sus documentos anejos. Achacamos esa imprecisión técnica, en la ley 30/1984, porque las plantillas orgánicas, con un carácter netamente heterogéneo, reflejan el conjunto de los puestos debidamente clasificados de un Centro o dependencia -en la terminología actual Centro Gestor- y las plantillas de los Cuerpos y lo Escalas, que tienen un carácter homogéneo, se refieren en exclusiva de los puestos reservados a los funcionarios pertenecientes a dichos cuerpos y/o Escalas, o incluso tan sólo a la pertenencia a un sólo Cuerpo pero con impacto presupuestario ${ }^{73}$. El EBEP ha prescindido directamente del concepto, aunque se presiente en el art. 73.3 cuando señala que los puestos de trabajo podrán agruparse en función de sus características para ordenar la selección, la formación y la movilidad. Puede intuirse que se está haciendo referencia a plantillas orgánicas porque no tendría lugar esta alusión directa a la "agrupación de puestos" cuando en el artículo siguiente se regula el sistema de ordenación de recursos humanos a través de las relaciones de puestos de trabajo u otros instrumentos organizativos similares.

Quizás, en el ámbito administrativo y organizativo, en donde se ha transmitido su sentido original y sus funciones, ha sido en la Administración local. En éstas realmente podemos hablar de un cumplimiento taxativo de sus disposiciones reguladoras. En efecto, las plantillas, que debían comprender todos los puestos de trabajo

69 STS, contencioso sección 1, del 19 de noviembre de 1994 (ROJ: STS 14216/1994) Recurso de revisión. En este mismo sentido, otorgando carácter normativo a los catálogos, la STS, contencioso sección 7, del 12 de diciembre de 1998 (ROJ: STS 7521/1998) № de Recurso: 8070/1992.

70 STS, contencioso sección 7, del 4 de enero de 2001 (ROJ: STS 37/2001) № de Recurso: 5220/1996.

71 Es el art. 52.3 del Decreto 315/1964, de 7 de febrero, por el que se aprueba la Ley articulada de Funcionarios Civiles del Estado. Pero también es importante destacar también el art. 53 que establece el contenido y relación de contenidos de dichas plantillas

72 Art. 14.3 de la Ley 30/1984, de 2 de agosto, de medidas para la reforma de la Función Pública. Los dos apartados siguientes, dedicados a las CC. AA. y las Entidades locales quedan sometidos al régimen de vigencia de la disposición final 4, por la disposición derogatoria única. b) de la Ley $7 / 2007$, de 12 de abril

73 Véase Entrena Cuesta, Rafael (1970) “Curso de Derecho Administrativo”. Ed. Tecnos. 3 a edición Pág. 406 y ss. 
clasificados reservados a funcionarios, personal laboral y eventual, deben aprobarse anualmente con ocasión de la aprobación del Presupuesto, de la misma forma que responder a los principios de racionalidad, economía y eficiencia. Todo ello, bajo la ordenación general de la economía, sin que los gastos de personal puedan rebasar los límites que se fijen con carácter general. A ellas se debían unir los antecedentes, estudios y documentos acreditativos del cumplimiento de los mencionados principios ${ }^{74}$. A esta norma, hemos de añadir las disposiciones del Reglamento de funcionarios de la Administración local de 1952, aún vigente en este extremo, cuando afirmaba sin lugar a duda alguna, que toda Corporación estará obligada a formar la plantilla de su personal, e identificando las consecuencias para responsables y gestores de la contravención de dicha obligación: "en ningún caso podrá expedirse nombramiento en propiedad, interino o accidental, ni satisfacer remuneraciones por empleos o cargos que no figuren en plantilla, y serán solidariamente responsables de las cantidades que se abonen con infracción de este precepto, el ordenador del pago y el interventor que no se opusiere a él75".

La jurisprudencia del Tribunal Supremo tiene clara la función que la ley atribuye a las plantillas y sus diferencias respecto a las RPT: "es asimismo necesario resaltar la distinta naturaleza y funcionalidad que la sentencia recurrida atribuye a la plantilla y a la relación de puestos de trabajo, pues ciertamente, al contener regulaciones de carácter presupuestario, el cumplimiento de las exigencias contenidas en el artículo 126.1 del Real Decreto Legislativo 781/1986, de 18 de abril , por el que se aprueba el Texto Refundido de las Disposiciones Legales Vigentes en materia de Régimen Local es predicable de la plantilla, pero no de la RPT. ${ }^{76 "}$. De ahí que la plantilla orgánica se convierta en un elemento básico del presupuesto de las Corporaciones locales: "Ia conexión entre plantilla y Presupuesto, dispuesta por la LRBRL (art. 90) y el TRRL (arts. 126 y 127), responde a la finalidad de que todos los puestos de trabajo de la Entidad local cuenten con la correspondiente dotación presupuestaria que permita la viabilidad económica de los mismos(...) No se trata, pues, de un vacío requisito formalista, sino de una exigencia sustantiva dirigida a hacer factible en términos económicos la Plantilla durante el ejercicio anual al que está referida, por lo que bastará para ello, como aquí aconteció, que en la fecha de inicio de ese ejercicio esté aprobada la dotación presupuestaria correspondiente a dicha Plantilla. $Y$ puede añadirse que esa exigencia de la dotación presupuestaria tiene sentido para los puestos de trabajo cuya continuidad se disponga o apruebe, pero no así para los que hayan sido objeto de supresión77». Por tanto, la medida de relación entre una y otra, plantilla orgánica y RPT, parece clara si juzgamos los pronunciamientos judiciales al respecto: "se desprende de estos preceptos que el instrumento técnico, el único, a través de cual se puede modificar el contenido de cada puesto de trabajo es la Relación de Puestos de Trabajo. En consecuencia, es evidente que este instrumento, al tener carácter excluyente de otros para configurar dicho contenido, vincula a las Plantillas Orgánicas, que, como dice la sentencia recurrida, tiene un marcado carácter presupuestario. En definitiva la aprobación de la Plantilla Orgánica no es sino la aprobación de una partida de los presupuestos, que podrá prever un número de funcionarios menor que el establecido en la Relación de Puestos de Trabajo (al existir por ejemplo vacantes que por motivos presupuestarios se decida no cubrir) pero que no puede contradecir en el contenido, naturaleza y número máximo de plazas, a las previsiones previstas en la Relación de Puestos de Trabajo78".

La vinculación entre el presupuesto municipal y la plantilla orgánica, lo es sobre la parte hacia el todo, ya que la modificación de las plantillas durante la vigencia del Presupuesto requerirá el cumplimiento de los trámites establecidos para la modificación de aquél y con unas condiciones que implican algunas operaciones presupuestarias de redistribución de los créditos de dotaciones para los gastos corrientes, en función siempre de establecimiento o ampliación de servicios de carácter obligatorio que resulten impuestos por disposiciones legales ${ }^{79}$. El Tribunal Constitucional, incluso, ha avalado la vinculación necesaria entre la creación de un Cuerpo, Escala, categoría o especialidad, su plantilla y el presupuesto anual: "Basta la mera lectura de ambas disposiciones adicionales para constatar que nos encontramos ante normas de neto contenido funcionarial, una vez que la primera de ellas se limita a crear una nueva Escala dentro de uno de los Cuerpos de la Administración Pública de la Comunidad Autónoma de Canarias -sin especificación alguna del número de plazas de las que habrá de constar ni tampoco de su dotación-, mientras que la segunda establece una consideración aclaratoria sin incidencia económica alguna que afectaría, en todo caso, al estatuto jurídico de otro cuerpo administrativo. En consecuencia, las mismas carecen absolutamente de

74 Art. 126 del Real Decreto Legislativo 781/1986, de 18 de abril, por el que se aprueba el Texto Refundido de las disposiciones legales vigentes en materia de Régimen Local

75 Art. 9 del Decreto de 30 de mayo de 1952 por el que se aprueba el texto del Reglamento de funcionarios de la Administración local. Son igualmente interesantes las admoniciones dirigidas a las autoridades y responsables locales sobre esta misma cuestión señaladas en el art. 10 y que constituyen un auténtico código ético a pesar de su derogación posterior: "Se formarán con rigurosa austeridad, a fin de atender los servicios, según los requiera su naturaleza, clase e importancia, con el mínimo de prestaciones, y en proporción a la cuantía del presupuesto"

76 STS, contencioso sección 7, del 17 de julio de 2012 (ROJ: STS 5483/2012) № de Recurso: 3547/2011.

77 STS, contencioso sección 7, del 28 de noviembre de 2007 (ROJ: STS 8631/2007). Nº de recurso: 1128/2003.

78 STS, contencioso sección 7, del 20 de octubre de 2008 (ROJ: STS 5629/2008) № de Recurso: 6078/2004.

79 A este respecto han de recordarse los arts. 26 y 27 de la Ley $7 / 1985$, de 2 de abril, reguladora de las Bases del Régimen Local y art. 30 del Decreto de 17 de junio de 1955, por el que se aprueba el Reglamento de Servicios de las Corporaciones Locales. 
conexión con los ingresos y gastos que conforman el Presupuesto, de modo que si bien, al menos en el primer caso, podrían tener en el futuro repercusiones presupuestarias, no pueden reputarse complemento necesario para la mayor inteligencia y para la mejor y más eficaz ejecución del actual Presupuesto (STC 130/1999, FJ 7) 80". $^{\circ}$.

Las diferencias entre ambas normas no es una simple diferencia formal, como aclara la jurisprudencia -aunque en este caso sea referida a las RPT-, pero que de manera analógica puede ser aplicado a las plantillas: "el hecho de que la RPT sea parte de la documentación acompañada a los presupuestos del Ayuntamiento, no basta para negar la distinta realidad jurídica de esa relación y los presupuestos mismos, (...) La diferenciación entre la índole jurídica de dos instrumentos normativos no puede tacharse en modo alguno de "argumento formalista", ni cabe tachar la referencia a tal diferenciación de modo de evitar el "pronunciarse sobre la legalidad del acuerdo que aprueba la RPT" 81. Por ello, difícilmente se puede hablar de una mera diferencia formal cuando ambas normas son contempladas por la LRBRL y atribuidas a un Órgano concreto a quien corresponde su aprobación, que tanto para los municipios de régimen ordinario como especial, corresponde al Pleno ${ }^{82}$. Precisamente, la determinación de las plantillas y su procedimiento de elaboración es una norma necesaria en las corporaciones locales y su carácter normativo ha sido recalcado por la jurisprudencia del Tribunal Supremo como hemos señalado. Los puestos incluidos en la plantilla orgánica son de imprescindible cobertura presupuestaria porque éste es el documento que soporta los gastos que se reflejan en las correspondientes partidas del presupuesto de gastos ${ }^{83}$. Esta cuestión ha sido afirmada con claridad manifiesta por parte de la jurisprudencia que determina su régimen jurídico peculiar y su carácter individualizado: "las plantillas son disposiciones generales, de carácter normativo y ordinamental, en las que, de acuerdo con las facultades que en el ámbito organizatorio interno corresponden a los entes públicos, se establece una relación y clasificación de los puestos de trabajo (...) para cuya vigencia es indispensable su publicación en periódico oficial, teniendo un procedimiento específico para su elaboración, que estuvo regulado en los arts. $9 .^{\circ} a$ 14 del Reglamento de Funcionarios de $1952^{84}$

En suma, tanto las RPT como los instrumentos previos y simultáneos analizados, constituyen en sí mismos una garantía del acierto y de observancia del principio de legalidad, en un asunto de trascendencia suma para el conjunto de los ciudadanos. No en vano, el art. 23.2 CE comienza por la observancia de los requisitos de elaboración y aprobación de las normas reguladores de plantillas, dotaciones presupuestarias suficientes y su correcto dimensionamiento. En el orden interno también son una garantía de los elementos estructurales básicos del estatuto de los funcionarios locales y de cuantos se han encuadrado en las organizaciones administrativas locales.

\section{NATURALEZA JURÍDICA DE LAS RPT}

La reciente STS, de 5 de febrero de 2014 ha venido a decantar la polémica jurisprudencial sobre la condición jurídica de las RPT, al señalar que se trata de "un acto-condición administrativo, ordenado y no ordenador de los efectivos públicos" pero lo ha hecho con un voto discordante de dos de los cinco magistrados componentes de la sección. Para estos últimos, "la relación de puestos de trabajo, no encaja, ciertamente, en los moldes tradicionales pero esa no es una característica exclusiva suya. El sistema de fuentes, el ordenamiento jurídico, ha ido, decíamos, adquiriendo una creciente complejidad. Y el ámbito del empleo público no es una excepción”. De ahí que consideren el cambio de doctrina casacional como altamente perjudicial para los empleados públicos mermando sus posibilidades y privándoles "del recurso de casación y, también, de la posibilidad de impugnar indirectamente las relaciones de puestos de trabajo con la consecuencia de que no podrán combatir sus actos de aplicación si no recurrieron en su día la resolución o acuerdo que las aprobó".

La jurisprudencia del Tribunal Supremo que se ha desplegado en los últimos años, de forma mayoritaria, ha resaltado el carácter de acto administrativo general con caracteres específicos que los acercan a las disposiciones normativas, e incluso se las ha calificado como acto plúrimo. Esta polémica se ha venido produciendo desde el

80 STC, del 15 de noviembre de 2000 (ROJ: STC 274/2000). Recurso núm. 1259/97.

81 STS, contencioso sección 7, del 20 de mayo de 2011 (ROJ: STS 3255/2011) Nº de Recurso: 1345/2009.

82 Ambos artículos son: el Art. 22.1.Corresponde al Pleno: i) La aprobación de la plantilla de personal y de la relación de puestos de trabajo, la fijación de la cuantía de las retribuciones complementarias fijas y periódicas de los funcionarios y el número y régimen del personal eventual. Y el art. Art.123.1, en los grandes municipios. Corresponde al Pleno: h) La aprobación de los presupuestos, de la plantilla de personal, así como la autorización de gastos en las materias de su competencia. Asimismo, aprobará la cuenta general del ejercicio correspondiente.

83 Hay que recordar que el capítulo $1^{\circ}$ de gastos corresponde al conjunto de gastos de personal en el presupuesto de cualquier administración pública. Efectivamente, en el ámbito local el Estado ha establecido la Orden EHA/3565/2008, de 3 de diciembre, por la que se aprueba la estructura de los presupuestos de las entidades locales. (BOE núm. 297 de 10 de Diciembre de 2008): CAPÍTULO 1 “Gastos de personal”. Se aplicarán a este capítulo los gastos siguientes: Todo tipo de retribuciones fijas y variables e indemnizaciones, en dinero y en especie, a satisfacer por las entidades locales y por sus Organismos autónomos al personal que preste sus servicios en las mismas. Las cotizaciones obligatorias de las entidades locales y de sus organismos autónomos a los distintos regímenes de Seguridad Social del personal a su servicio. Las Prestaciones sociales, que comprenden toda clase de pensiones y las remuneraciones a conceder en razón de las cargas familiares. Los Gastos de naturaleza social realizados, en cumplimiento de acuerdos y disposiciones vigentes, por las entidades locales y sus organismos autónomos para su personal.

84 STS, contencioso sección 1, del 26 de diciembre de 1990 (ROJ: STS 1513/1990) Recurso de apelación. 
primer pronunciamiento jurisdiccional sobre las RPT, la STS de 20 de septiembre de 1988, ya que su definición conceptual como "elemento normativo desgajado" no propició un camino unívoco acerca de su naturaleza jurídica. A ello tampoco ha contribuido la regulación específica en la Administración General del Estado que ha permanecido inalterada desde su publicación inicial tal y como hemos destacado más arriba.

Aunque la STS de 5 de febrero de 2014 pudiera dar a entender que era la "crónica de una muerte anunciada", sin embargo, creemos que, con los "mimbres" normativos actuales y también la línea jurisprudencial seguida no mucho antes de que se decantara el propio Tribunal Supremo sobre su consideración como disposición general a los solos efectos procesales casacionales, es posible concluir su carácter claramente normativo. Algo en lo que el voto particular de la precitada sentencia parece creer cuando afirma que "esta figura, la RPT, no encaja, ciertamente, en los moldes tradicionales pero esa no es una característica exclusiva suya. El sistema de fuentes, el ordenamiento jurídico, ha ido, decíamos, adquiriendo una creciente complejidad". Carácter que se reafirma al ser instrumento ordenador de la organización administrativa en sus niveles más elementales, y como resultado natural y lógico del ejercicio de las potestades de organización, tal y como se señala en la Ley de Organización y Funcionamiento de la Administración General del Estado:"las unidades administrativas se establecen mediante las relaciones de puestos de trabajo, que se aprobarán de acuerdo con su regulación específica, y se integran en un determinado órgano ${ }^{85}$ “. Este último extremo parece haber sido pasado por alto en los repetidos pronunciamientos jurisdiccionales.

A nuestro juicio la doctrina del "elemento normativo desgajado", a la que hemos hecho alusión, por sus consideraciones netamente normativas y, por tanto, reglamentarias ofrece fundamentos doctrinales suficientes, además de añadirse a la cuestión a una reconsideración sobre las dos principales funciones de las RPTs: ser instrumento, en primer término, de la ordenación y planificación de recursos humanos, y delimitador de la carrera funcionarial, y, en segundo, como máximo exponente de la potestad de organización de la Administración. Es verdad que la construcción doctrinal del "elemento normativo desgajado" ha tenido sus orígenes hace ya algún tiempo pero fue adoptada de forma repetida por la jurisprudencia del Tribunal Supremo para las nuevas figuras normativas intermedias, algunas de las cuales finalmente fueron catalogadas por aquélla como normas reglamentarias, caso de los Planes de Ordenación urbana.

\subsection{Elemento normativo desgajado}

La jurisprudencia ha señalado que el elemento normativo desgajado, se halla plenamente consolidado como tal, y se define como "una unidad jurídica intermedia entre el acto y la norma ${ }^{86 ", ~ " c o m o ~ u n a ~ s u e r t e ~ d e ~ t e r t i u m ~ g e n u s ~}{ }^{87}$ " que tiene "contenido de norma y envoltura de acto ${ }^{88 "}$ y que, en modo alguno se contrapone entrambos, ya que la distancia se manifiesta a través de una gradación jurídica entre los tipos normativos y los singulares. La elaboración jurisprudencial, es reflejo de la propiamente doctrinal (VILLAR PALASÍ y MEILÁN ${ }^{89}$ ) y la considera aplicable ya que "es posible detectar(la) en toda institución jurídica: personal(idad), contratación, patrimonio, relación servicial pública, fuentes de producción del ordenamiento- se manifiesta, en el caso concreto del plan urbanístico, en forma de jerarquía y consiguiente subordinación de unos planes a otros ${ }^{\circ}$. Por tanto, la calificación como "elemento normativo desgajado" no ha sido propia y exclusiva de las RPT, aunque el antecedente más cercano a éstas en el ámbito de la función pública anterior a la Ley 30/1984, ya era considerado como tal elemento normativo desgajado: “cualquiera sea la matización que, desde el punto de vista de su naturaleza jurídica como disposiciones generales o reglamentarias (...) lo cierto es que se trata, al menos, de lo que doctrinalmente se ha calificado como regulación de "elementos normativos desgajados", propia del escalonamiento en la normación de éstos funcionarios de Organismos autónomos, así como también lo es que, con independencia de su mayor o menor pureza conceptual, la Administración de la que emanó el Decreto impugnado le dio, cabalmente, el tratamiento de norma y no de acto ${ }^{91 "}$

De hecho, esta doctrina se ha aplicado, por ejemplo, de forma temprana tanto a los Planes parciales de Ordenación Urbana --hasta su consideración como norma reglamentaria plena92-- como a un Decreto del Gobierno de Canarias, por el que se modifica el Reglamento de Organización y Funcionamiento del Servicio Jurídico del Gobierno de Canarias ${ }^{93}$, también a los decretos de declaración de parque natural94, como a una Orden ministerial

85 Art. 7 de la Ley 6/1997, de 14 de abril, de Organización y Funcionamiento de la Administración General del Estado.

86 STS, contencioso sección 3, del 3 de marzo de 1995 (ROJ: STS 8612/1995) Recurso de apelación.

87 STS, contencioso sección 4, del 11 de octubre de 2011 (ROJ: STS 6355/2011) N de Recurso: 34/2010.

88 STS, contencioso sección 1, del 29 de septiembre de 1989 (ROJ: STS 4954/1989).

89 Para ello consúltese: Meilán Gil, José Luis (1967) “La distinción entre norma y acto administrativo”. Publicaciones de la Escuela Nacional de Administración Pública. Ed. BOE. Madrid y Villar Palasí, José Luis y Villar Ezcurra, José Luis (1999) “Principios de Derecho Administrativo”. Tomo I. Servicio de Publicaciones de la Universidad Complutense de Madrid

90 STS, contencioso sección 1, del 25 de junio de 1986 (ROJ: STS 3608/1986).

91 STS, contencioso sección 5, del 21 de febrero de 1979 (ROJ: STS 2959/1979) Nº de Resolución: $101 / 1979$.

92 STS, contencioso sección 1, del 25 de junio de 1986 (ROJ: STS 3608/1986).

93 STS, contencioso sección 7, del 15 de septiembre de 2005 (ROJ: STS 5307/2005) N de Recurso: $1284 / 2000$.

94 STS, contencioso sección 4, del 11 de octubre de 2011 (ROJ: STS 6355/2011) N de Recurso: 34/2010. 
sobre retribuciones de personal sanitario y no sanitario dependientes del Instituto Nacional de la Salud ${ }^{95}$. Aunque, también esta misma jurisprudencia acaba por reconocer que dicha categoría jurídica es más propiamente la del acto administrativo: "con la diferenciación entre norma y acto, la cual se difumina con la presencia de eso que se ha dado en llamar <<elementos normativos desgajados>>, cuyo régimen jurídico diverge del de la norma y del que es propio del acto ${ }^{96 "}$.

En efecto, todos estos ejemplos participan de una u otra forma, de un indudable contenido normativo aunque siempre haciendo hincapié en un concepto mixto o híbrido, de una institución de doble naturaleza, a modo de un escalón más entre la norma y el acto administrativo tratando de esta manera de compatibilizar la nuevas categorías y /o conceptos surgidos de la realidad administrativa con los ya consagrados en nuestro derecho administrativo. Sin embargo, dicha operación no pasa de ser una respuesta del momento, "pragmática", necesitada de una mayor consolidación, sobre todo en el terreno conceptual. Aunque no falta también - quizás más sistemática esta corriente- una línea jurisprudencial en la que se afirma de forma rotunda que el elemento normativo desgajado es una específica manifestación de potestad normativa-específica porque su ejercicio no exige ajustarse al procedimiento de elaboración de disposiciones generales- que precisamente por su peculiaridad, lo es de forma menos rigurosa que cuando se trata de Reglamentos "lato sensu". Para ello, se ha basado en elementos característicos de los disposiciones generales que la misma jurisprudencia ha ido fraguando en torno a ellas, caracterizando "lo normativo" como propio de los elementos normativos desgajados: a) Indeterminación de los destinatarios, como sucede en las Sentencias de la antigua Sala Cuarta de 9 de febrero de 1959, de la Sala Tercera de 9 de julio de 1962 y en la de la antigua Sala Cuarta de 25 de julio de 1963. b) Producción de efectos de alcance y contenido general, como indica la Sentencia de la antigua Sala Cuarta de 29 de mayo de 1965. c) El carácter futuro de los supuestos de hecho que haya de aplicarse o la finalidad aclaratoria e interpretativa, como reconoce la Sentencia de la antigua Sala Quinta de 11 de diciembre de 1964 d) El carácter organizador, como reconoce la Sentencia de la antigua Sala Cuarta de 22 de octubre de 1965. e) Entre otros, los criterios relativos a la integración e innovación en el ordenamiento jurídico, como reconocieron las Sentencias de la antigua Sala Quinta de 12 de febrero de 1966 y 28 de noviembre de 1961. f) En una evolución posterior de la doctrina jurisprudencial, se asume la tesis ordinamentalista que sostiene que el Reglamento forma parte del ordenamiento y el acto administrativo, aunque su contenido sea general o se refiera a una pluralidad indeterminada de sujetos, no forma parte del ordenamiento jurídico, lo que ha hecho clásica la descripción del acto ordenado no ordinamental y esta tesis proporciona una clave precisa para fijar la línea divisoria entre el acto y la norma, bajo genéricos conceptos como «potestad reglamentaria» o «Reglamentos» se cobijan diversa suerte de potestades — del mismo género, pero de distinta calidad-y normas que aunque comparten secundario rango cumplen funciones material e incluso constitucionalmente distintas, lo que obliga a aislar sus elementos diferenciales y a analizar qué consecuencias o efectos producen o debieran producir" ${ }^{97}$. A estas características hemos de señalar que dichos elementos normativos poseen además eficacia "ad extra" con imposición de cargas y obligaciones, aunque también de derechos ${ }^{98}$.

Todas estas características son comunes a los elementos normativos desgajados y son la piedra de toque para entender -a pesar del reciente cambio jurisprudencial- que las RPT tienen un contenido normativo real y no aparente, y menos a los meros efectos procesales porque esto último es, en efecto, una mera "fictio iuris" como afirma la STS de 5 de febrero de 2014. La consideración, pues, de las RPT como elementos normativos desgajados con una naturaleza de disposición general es un argumento que, desde una configuración doctrinal diseñada tiempo atrás y traída por una jurisprudencia temprana desarrollada por el Tribunal Supremo sobre esta figura y otras semejantes, necesita de un complemento indispensable y es el carácter de norma producto del ejercicio de la potestad organizativa del complejo Gobierno - Administración, o desde el plano "reglamento orgánico- Pleno / Junta de Gobierno" en el ámbito local.

\subsection{Carácter normativo de las RPT. Líneas jurisprudenciales ${ }^{99}$}

Es cierto que la jurisprudencia respecto a las RPT ha sido titubeante e incluso contradictoria ${ }^{100}$, acabando por señalar -previamente al cambio operado por esta sentencia-- que su verdadera sustancia jurídico-administrativa

95 STS, contencioso sección 1, del 20 de septiembre de 1988 (ROJ: STS 6338/1988).

96 STS, contencioso sección 6, del 6 de noviembre de 1999 (ROJ: STS 7011/1999) Nº de Recurso: 6266/1995.

97 STS, contencioso sección 7, del 2 de junio de 1999 (ROJ: STS 3895/1999) No de Recurso: 4727/1993 (F J. $2^{\circ}$ ).

98 STS, contencioso sección 5 del 13 de diciembre de 2013 (ROJ: STS 6010/2013) Nº de Recurso: $1003 / 2011$.

99 A este respecto resulta especialmente útil las consideraciones de González Navarro respecto al concepto de línea jurisprudencial: González Navarro, Francisco (1987) “De las jurisprudencias y de las líneas jurisprudenciales”. Actualidad Administrativa. № 39.

100 La STS, contencioso sección 7, del 12 de noviembre de 2008 (ROJ:STS6185/2008) № de Recurso: 10749/2004, incurre en un formalismo extremo al vincular la naturaleza de la RPT al "manto jurídico" que la envuelve: "si bien este Tribunal ha atribuido a los acuerdos sobre regulación de la RPT, a veces, la naturaleza de normas, ello lo ha sido a los solos efectos de admisibilidad de la casación, o en algún caso excepcional cuando la regulación o modificación de la RPT se contiene en un instrumento jurídico, que por su forma de exteriorización, procedimiento de elaboración y modo de publicación, e incluso por su contenido añadido, justifica que se le asigne esa naturaleza reglamentaria" 
es la de los actos plúrimos, con destinatarios indeterminados, de donde viene aquella denominada vocación normativa, pero excluyendo en todo caso que sean auténticos reglamentos, con un acceso al recurso de casación precisamente por este contenido normativo.

Pero también es indudable que existió una línea jurisprudencial muy clara a favor del carácter normativo de las RPT. Carácter que la STS de 5 de febrero de 2014 curiosamente se reconoce a las RPT de otras Administraciones públicas distintas a la $A G E^{101}$. Tal vez sea porque, en una sentencia poco tiempo anterior, se decía "en esencia" lo contrario a lo que ahora se concluye: que las Relaciones de Puestos de Trabajos de los Ayuntamientos deben ser consideradas una disposición general en cuanto "regula el régimen jurídico, organizativo, económico, etc., de los puestos de Trabajo y ese régimen se establece con vocación de permanencia" tal como se declara en STS, de 19 de Noviembre de 1.994. (...) Por otra parte, las actuaciones administrativas de formación de Relación de Puestos de Trabajo han sido calificadas jurisprudencialmente como actuaciones administrativas de naturaleza normativa, dado su carácter ordinalmente y notas de generalidad, abstracción y permanencia que ellas concurren, por lo que el procedimiento de aprobación ha de adaptarse a esta finalidad de elaboración de un instrumento de contenido normativo ${ }^{102}$. De la misma forma que no es entendible, como se deduce fácilmente de los fundamentos de la sentencia, que algo puede ser y no ser a la vez, o que posea una naturaleza jurídica para algunas cosas y otra diferente en otras. Tampoco es entendible que las RPT, --dado que ésta es en sí misma una opción frente a otros modelos organizativos (ex art. 74 EBEP)--, sea en una Administración "acto plúrimo" y en otra "norma general”, máxime cuando estamos ante materia normativa básica para todas las Administraciones públicas y que en determinados ámbitos supone un principio de la interterritorialidad de determinados cuerpos de funcionarios como afirma el Tribunal Constitucional a los efectos de señalar precisamente esta peculiaridad corporativa ${ }^{103}$.

En efecto, ya la STS del 10 de julio de 2013, realizó un amplio resumen sobre la doctrina jurisprudencial al respecto y de las constantes dificultades a la hora de definir la naturaleza jurídica de las relaciones de puestos de trabajo, pero subrayando el sólido planteamiento de atribución del carácter normativo "dadas las notas de generalidad, abstracción y permanencia que en ellas concurren, diferenciándolas de los actos con destinatario plural $e$ indeterminado pero carentes de contenido normativo ${ }^{104 "}$ ". En esta doctrina jurisprudencial queremos apoyar nuestras consideraciones. Es decir que las RPT son "per se" auténticas disposiciones normativas de carácter general. En efecto, de las enunciadas en la anterior cita, se afirma sin duda alguna que las RPT son normas jurídicas "consiguientemente, teniendo las R.P.T. naturaleza normativa (pues así lo reconoce la jurisprudencia de este Tribunal en las sentencias, entre otras, de 3 marzo y 25 de abril de 1995, 13 y 28 mayo y 4 junio de 1996, y 3 de octubre de $2000 . . .105$ ". Y en otra se dice: "ni se impugna una disposición general (naturaleza jurídica que efectivamente es predicable de las relaciones de puestos de trabajo) ni la cuestión de personal objeto del recurso se refiere al nacimiento o extinción de la relación de servicio de funcionarios de carrera. ${ }^{106 " ~ I n c l u s o ~ s e ~ l a s ~ h a ~ l l e g a d o ~ a ~ d e n o m i n a r ~ c o m o ~ " a c t o ~}$ normativo": "y es que la primera y única determinación de las características esenciales de los puestos de trabajo no puede ser la que contengan las respectivas convocatorias. Con carácter previo, dichas características esenciales han de haber sido anticipadas por el acto normativo que aprueba o modifica los tan repetidos puestos de trabajo ${ }^{107}$ ". $Y$ quizás la más indefinida al respecto, es la que asegura que su carácter de norma jurídica viene dado por el examen de su propio contenido.

De todas la características definitorias de una disposición de carácter general, sin duda, la mayor y mejor, es su “ingreso" en el Ordenamiento jurídico, así lo señalaba gráficamente PARADA VAZQUEZ al afirmar que el acto

101 "no cabe que de modo apriorístico dichas consideraciones deban ser necesariamente aplicables también a las Relaciones de Puestos de Trabajo de Administraciones de las Comunidades Autónomas y de las Entidades Locales" ya que "deberá estarse como factor principal para cualquier posible análisis a lo que disponga la Ley de la Función Pública de cada Comunidad Autónoma, dentro de los límites marcados al respecto por la legislación básica del Estad". FJ $2^{\circ}$ de la STS, contencioso sección 7, de 5 de febrero de 2014 (ROJ: STS 902/2014) N de Recurso: 2986/2012 Ponente: VICENTE CONDE MARTIN DE HIJAS.

102 STS, contencioso sección 7, del 17 de julio de 2012 (ROJ: STS 5483/2012) Nº de Recurso: 3547/2011.

103 "Como razonamos en la STC 253/2005, de 11 de octubre, y ratificamos en la STC 163/2012, FJ 6 j), "la regulación de la Ley Orgánica del Poder Judicial relativa a las relaciones de puestos de trabajo ... constituye un régimen jurídico a través del cual el Estado garantiza la unidad y homogeneidad de estos cuerpos de funcionarios al servicio de la Administración de Justicia ..., asegurando así la movilidad de aquéllos en todo el territorio nacional" (FJ 8)" STC, del 29 de noviembre de 2012 (STC 224/2012) Recurso de inconstitucionalidad núm. $1933 / 2004$.

104 STS, contencioso sección 7, del 10 de julio de 2013 (ROJ: STS 4323/2013) № de Recurso: 2598/2012. Se cita dentro de la propia sentencia otras desde las que se sigue la línea jurisprudencial: STS de 13 febrero 2001, Rec. de Casac. $n^{\circ} 840 / 2000,20$ de febrero de 2001 , Rec. de Casac $n^{\circ}$ 1040/2000, que se remite a las sentencias de 3 de marzo y 25 de abril, 13 y 28 de mayo 1996, 4 de junio de 1996 ó 3 de octubre de 2000).

105 STS, contencioso sección 1, del 13 de febrero de 2001 (ROJ: STS 965/2001) № de Recurso: 840/2000.

106 STS, contencioso sección 1, del 3 de octubre de 2000 (ROJ: STS 7035/2000) N de Recurso: 548/1999. En este mismo sentido y junto a las mencionadas en la nota 28, la STS, contencioso sección 1, del 5 de diciembre de 2000 (ROJ: STS 8949/2000) N de Recurso: 976/2000; la STS, contencioso sección 1, del 20 de febrero de 2001 (ROJ: STS 1191/2001) № de Recurso: 1037/2000; y la STS, contencioso sección 1, del 25 de abril de 1995 (ROJ: STS 9067/1995) Recurso de apelación.

107 STS, contencioso sección 7, del 12 de noviembre de 2006 (ROJ: STS 7414/2007) Nº de Recurso: $11049 / 2004$. 
administrativo es "flor de un día” porque no tiene ninguna vocación de permanencia que es lo característico de las normas, siendo más precisa la separación acto administrativo y reglamento mediante el criterio ordinamental de la no consunción ${ }^{108}$. Criterio ordinamentalista que también se ha reflejado en la propia jurisprudencia, primero sobre los elementos normativos desgajados, y luego sobre las RPT: “la naturaleza de disposición de carácter general o acto administrativo no viene determinada simplemente por una diferencia cuantitativa, destinatarios generales o indeterminados para el reglamento y determinados para el acto administrativo, sino que la diferencia sustancial entre disposición de carácter general y acto administrativo es una diferencia de grado, o dicho de otro modo, la diferencia está en que el reglamento innova el ordenamiento jurídico con vocación de permanencia) ${ }^{109 "}$. A este respecto debe señalarse que, en efecto, la aplicación de una RPT sobre el contenido de derechos y obligaciones de los funcionarios no se "consume", a modo de ejemplo, por el desempeño de un puesto de trabajo concreto, y el haz de relaciones creadas con quien lo desempeñe que despliega derechos continuados y "ad futurum". Actos que vuelven a desplegar sus efectos cuando aquel funcionario abandone el puesto de trabajo y sea ocupado por otro. Es decir, la permanencia en el tiempo de la RPT es innegable, contrastando con el acto plúrimo por excelencia que son las convocatorias de pruebas de acceso a un Cuerpo de funcionarios. Constituyen, pues, derecho objetivo. Hecho reflejado por otra línea jurisprudencial al admitir el recurso indirecto por vía del art. 26 de la LRJCA ${ }^{110}$, a pesar de la existencia de una línea minoritaria también contraria111.

Otra circunstancia también aclaratoria del contenido normativo de las RPT es la jurisprudencia reciente, articulada por la sala, cuando señala que en el caso de una RPT que reproduce otra anterior, no se puede hablar de acto consentido, siendo posible una nueva impugnación directa: "cuando se aprueba una RPT, aunque sea una modificación parcial, al igual que ocurre con los reglamentos, se abre la posibilidad de su impugnación directa, (...). Es decir, esta Sala viene admitiendo que cuando una RPT reproduce otra anterior, no se puede hablar de acto consentido, y es posible su impugnación ${ }^{112}$.

De lo que no cabe duda alguna es que, en toda la larga serie jurisprudencial sobre las RPT, se ha manifestado el indudable carácter normativo de éstas, aunque "eclipsado" por su condición de acto administrativo general, como también se afirmaba frecuentemente por la misma jurisprudencia y, sobre todo, al detenerse de forma exclusiva en su carácter de instrumento de ordenación del personal y, por el contrario, no en su carácter también netamente organizador de las estructuras administrativas. Este último aspecto parece estar más presente en la STS de 5 de febrero de 2014, al señalar "que no cabe que de modo apriorístico dichas consideraciones deban ser necesariamente aplicables también a las RPTs de Administraciones de las Comunidades Autónomas y de las Entidades Locales", dado que las RPT en el ámbito de las Administraciones locales -quizás sea porque considere el Tribunal Supremo que son la máxima expresión de la autonomía local--, tienen también un indudable efecto organizador de las Administraciones locales.

A pesar de la línea argumental expresada más arriba, la nueva doctrina jurisprudencial acuñada por la STS de 5 de febrero de 2014 aunque sea desde la perspectiva del "acto condición administrativo ordenado" tampoco empece para que las RPT sigan teniendo una extraordinaria importancia en la carrera administrativa de los funcionarios públicos locales ya que son las verdaderas posibilitadoras de su movilidad intra e interadministrativa dentro del sistema actual de “desempeño de puesto de trabajo". Pero si se quisiera ir más allá y regular un modelo de carrera ex art. 74 del EBEP, dentro de los contornos que sobre esta cuestión prevé la actual normativa básica local, de la que hemos dado cuenta en apartados anteriores, han de otorgarse a las RPT un carácter normativo claro por parte del legislador local. En cualquier caso, este es un ejercicio característico de la autonomía local para el que el legislador tiene vedada toda regulación de la capacidad decisoria de los entes locales respecto de las materias de su interés que se sitúe por debajo de ese umbral mínimo que les garantiza su participación efectiva en los asuntos que les atañen y, por consiguiente, su existencia como reales instituciones de autogobierno ${ }^{113}$.

\section{BIBLIOGRAFÍA}

Álvarez Álvarez, Julián “Neutralidad política y carreraadministrativa delosfuncionariospúblicos” Documentación Administrativa-1987, núms. 210-211.

Entrena Cuesta, Rafael (1970) “Curso de Derecho Administrativo". Ed. Tecnos. 3 a edición.

108 Parada Vázquez, Ramón (2010) “Derecho Administrativo I”. 18a edición. Ed. Marcial Pons. Pág. 71.

109 STS, contencioso sección 7, del 10 de julio de 2013 (ROJ: STS 4323/2013) № de Recurso: 2598/2012 | Ponente: JOSE DIAZ DELGADO FJ. $4^{\circ}$.

110 STS, contencioso sección 7, de 19 de julio de 2007 (ROJ: STS 5352/2007) № de Recurso: 182/2005.

111 Destaca las Sentencias de 4 de Julio de 2012 -Recurso de casación nº 1984/2010, F.J. 5; y de 10 de julio de 2013 -Recurso de casación $n^{\circ} 2598 / 2012$.

112 STS, contencioso sección 7, del 13 de diciembre de 2013 (ROJ: STS 6218/2013) № de Recurso: 1914/2011.

113 STC, del 19 de junio de 2012 (STC 132/2012) Recurso núm. 6433/2000. 
Fuentetaja Pastor, Jesús Ángel (2013) "La función pública local: asignatura pendiente de la autonomía local" Revista de Administración Pública, nº 191.

González Navarro, Francisco (1987) "De las jurisprudencias y de las líneas jurisprudenciales". Actualidad Administrativa. $\mathrm{N}^{\circ} 39$.

Gutiérrez Reñón, Alberto (1987) “La carrera administrativa en España: histórica y perspectivas”. Documentación Administrativa. Núms. 201-211.

Meilán Gil, José Luis (1967) "La distinción entre norma y acto administrativo". Publicaciones de la Escuela Nacional de Administración Pública. Ed. BOE. Madrid.

Parada Vázquez, Ramón (2007) “Derecho del Empleo Público. La la Ley 7/2007, de 12 de abril, del Estatuto Básico del Empleado Público". Ed. Marcial Pons. Madrid. 2007.

Parada Vázquez, Ramón (2010) “Derecho Administrativo l”. 18ª edición. Ed. Marcial Pons.

Sánchez Morón, Miguel (2000) “Derecho de la función Pública”. 2 edición -reimpresión-. Ed. Técnos. Madrid.

Villar Palasí, José Luis y Villar Ezcurra, José Luis (1999) “Principios de Derecho Administrativo”. Tomo I. Servicio de Publicaciones de la Universidad Complutense de Madrid. 